\title{
An Analysis of the Repertoire Chosen for the Cello Volumes of the Suzuki Method
}

\author{
By \\ Rebecca Jane Anna Harvey
}

A thesis submitted to the Victoria University of Wellington in fulfilment of the requirements for the degree of Master of Music in Performance

Victoria University of Wellington 2020 


\section{Abstract}

This dissertation is directed towards cello pedagogues inside and outside the Suzuki community. It provides a deeper understanding of the origins and philosophy of the Suzuki method, an in-depth analysis of the musical works chosen for each of the Suzuki Cello Method books, and a discussion on the decision to include Suzuki editions of two standard cello concertos as part of the Method. In addition, the thesis covers some common criticisms towards the Suzuki Method. 
To my husband - your love, support, and encouragement have been very much appreciated and instrumental in the writing of my thesis. I love you so much $\mathrm{xx}$ 


\section{Acknowledgments}

A very special thank you to my supervisor Donald Maurice for your guidance and support this year, and to Sally-Anne Alloway for your input into the thesis both through the interview regarding Chapter Eight of the thesis and during the last four units of Suzuki Teacher Training that I have taken with you. Your knowledge and wisdom have been invaluable, and I am beyond grateful to you both. Thanks also to my first cello teacher Emma Goodbehere, you instilled a love of the cello in me and demonstrated how inspiring a good Suzuki teacher can be. To Rolf Gjelsten and Inbal Megiddo, thank you for your guidance and support over the last five years and for teaching me so much about music and about life. And finally to Veronica Pot for your support and wisdom and for reading so much of what I wrote. Your feedback was so valuable and I am so thankful for your friendship too. 


\section{Contents}

$\begin{array}{ll}\text { Abstract } & \text { ii }\end{array}$

Introduction 1

Chapter One: The History and Philosophy of the Suzuki Method 3

Shinichi Suzuki: Founder and Facilitator of the Suzuki Method

The Philosophy

Chapter Two: The Early Volumes

Suzuki Cello Volume One

Suzuki Cello Volume Two

Chapter Three: Getting to Know the Positions and Techniques

Suzuki Cello Volume Three

Suzuki Cello Volume Four

Chapter Four: Consolidating the Positions and Techniques

26

Suzuki Cello Volume Five

Chapter Five: The Higher Positions

Suzuki Cello Volume Six

Suzuki Cello Volume Seven

Chapter Six: The Professional Repertoire

Suzuki Cello Volume Eight

Chapter Seven: The Concertos

Suzuki Cello Volume Nine

Suzuki Cello Volume Ten

Beyond Volume Ten

Chapter Eight: Common Criticisms

Conclusion

Bibliography 


\section{$\underline{\text { Introduction }}$}

Since the end of the Second World War, music education for children has had a world-wide soaring in popularity. Immediately after the war, the "Dutch "Ministry" initiated a series of commissions and study groups specifically designed to address the problems confronting music education in the Netherlands." In America, the National Association for Music Educations (formerly Music Educators National Conference) published a bill of rights on March 21, 1950, detailing that every child should have access to a "program of music instruction in school taught by teachers qualified in music." 2 In England, the 1944 Education Act "recommended a range of musical activities in secondary schools."

Perhaps the greatest cause of the rise in music education after the war can be attributed to Shinichi Suzuki, Japanese violinist and founder of the Suzuki Method. Suzuki began teaching small children and developing his methodology and philosophy as early as 1930. In 1946 he opened the Matsumoto Music School, and the Talent Education Research Institute (which became authorised by the Ministry of Education) was founded in 1950. Suzuki's philosophy and methodology spread to other cities and countries, and today teachers in at least 38 different countries use the Suzuki method.

This dissertation is aimed towards cello pedagogues inside and outside the Suzuki community. For readers not yet familiar with the Suzuki Method, Chapter One of this dissertation offers the chance to gain an enriched understanding of the Suzuki methodology and philosophy. For those who participate in the Suzuki Method, as teachers, parents, and past or present students, Chapter One of this dissertation gives historical information and knowledge of which the reader may be unaware.

Chapters Two through Seven consist primarily of an in-depth analysis of the musical works chosen for each of the Suzuki Cello Method books. For the non-Suzuki reader, this will

\footnotetext{
${ }^{1}$ Luxenberger, C. (1997). The developing role of the recorder in the conservatories and music schools of the Netherlands from post-World War II to 1980. Ph.D. University of Houston. p.122.

2 The National Association for Music Educations. (2008). Child's Bill of Rights. [online] Available at: https://web.archive.org/web/20080929204920/http://www.menc.org/resources/view/child-s-bill-of-rights [Accessed 17 May 2019].

${ }^{3}$ Rainbow, B. (2013). Music Education, Yesterday, Today and Tomorrow. In Dickinson P. (Ed.), Music Education in Crisis: The Bernarr Rainbow Lectures and Other Assessments (pp. 129-138). Woodbridge, Suffolk, UK; Rochester, NY, USA: Boydell \& Brewer.
} 
explain the technical developments through the method books and give an understanding of the logical progression the Suzuki cello student makes as they work their way through the ten volumes. Readers familiar with the Suzuki method will each take away ideas relevant to themselves and their situation, and potentially gain a new perspective on their own approach as a teacher or parent. Chapter Seven also discusses the decision to include Suzuki editions of two standard cello concertos as part of the Method. The historical background and context to these works is explained and the relevance of these works to the Suzuki student is explored.

In the eighth and final chapter of this thesis, two of the most common criticisms towards the Suzuki method are discussed: sightreading and rote learning. It is my hope that this chapter may shed some light on misconceptions and to encourage those unfamiliar with the method to reassess their perceptions of the Suzuki Method. This chapter may also equip readers in the Suzuki community with knowledge applicable in situations where they have queries about these aspects of the method. 


\section{Chapter One: The History and Philosophy of the Suzuki Method}

\section{Shinichi Suzuki: Founder and Facilitator of the Suzuki Method}

Shinichi Suzuki was born in Nagoya, Japan on the 17th October 1898, and died at age 99 in Matsumoto on the 27th January 1998. His father was a violin-maker and Suzuki was brought up with his six brothers and five sisters in the violin factory. ${ }^{4}$ Although they were surrounded by violins, Suzuki did not show any interest in music as a child. It was quite the contrary: as Suzuki himself said, "At times, when I had a fight with my brothers and sisters, we would hit one another with violins."

It was only in his late teenage years that Suzuki picked up the violin to use it for what it was intended, after hearing a recording on an early gramophone player. Suzuki describes his experience thus:

The first record I bought was Schubert's "Ave Maria" played by Mischa Elman. The sweetness of the sound of Elman's violin utterly enthralled me. His velvety tone as he played the melody was like something in a dream. It made a tremendous impression on me. To think that the violin, which I had considered a toy, could produce such beauty of tone! ${ }^{6}$

This recording opened Suzuki's eyes to music, and from that day on he began a life-long search for the true meaning of art. The first piece that he learnt was a Haydn minuet*. Suzuki brought a violin home from the factory and imitated daily a recording until he could finally play the piece. Suzuki "derived great comfort from playing the violin, and became very fond of the instrument as well as developing deep love for music."7

Suzuki's father agreed to fund his son's music studies, and in his early twenties, Suzuki travelled to Berlin to study music. While in Germany, he had great difficulty in picking up the German language, and he began to recognise the incredible intellectual ability of younger

\footnotetext{
${ }^{4}$ Hermann, E. (1981). Shinichi Suzuki: The Man and His Philosophy. Miami, FL: Summy-Birchard Music, p.5.

${ }^{5}$ Carpenter, S. (1988). Shinichi Suzuki and His "Mother-Tongue Approach" to Music Education in the United

States. Unpublished Master of Fine Arts Thesis, University of Florida, Gainesville, FL. p.6.

${ }^{6}$ Suzuki, S. (1969). Nurtured by Love. Miami, FL: Summy-Birchard, Inc.. p.68-9.

${ }^{7}$ Ibid.

* Suzuki does not write which minuet he learnt.
} 
children, as they are able to learn languages with ease. Almost a decade later Suzuki returned to Japan to help his family who were going through financial challenges, and he decided to take up violin teaching. While back in his homeland he was asked to teach some young children to play the violin, and he discovered that he enjoyed the new challenge. As his family owned the violin factory, Suzuki requested of his brother a small violin, about the size that a child aged four years could manage. ${ }^{8}$

Teaching these younger children led to Suzuki's realisation that children learn to speak a language very quickly, and they do so through immersion in the language, constant repetition, and parental encouragement. Suzuki's discovery of these principles led to the development of the teaching method that we know today as the Suzuki Method. After having success with his first students as early as 1930, in 1946 the "Matsumoto Music School" was established in Matsumoto, Japan. Through Suzuki's efforts, the influence of this school gradually increased, and by 1949 there were multiple branches of violin classes all teaching under this same philosophy. In 1950, the organisation "Talent Education Research Institute" was developed and authorized by Japan's Ministry of Education. Currently, teachers from all over the world travel to Matsumoto to participate in Suzuki Teacher Training, and the programme has expanded to include cello, viola, flute, piano, double bass, recorder, guitar, harp and voice. ${ }^{9}$

Suzuki's realisations and subsequent philosophy of teaching music revolutionised the musical world, and Dr Lydia Mordkovich, professor of violin at the Royal Academy of Music in London, said that Suzuki was "single-handedly responsible for a worldwide soaring interest in the violin after the Second World War."10 She said that the violin is "such a very, very complicated instrument to learn, especially for young children. Suzuki found a way to make it approachable for kids. He was a great man and an absolutely wonderful pioneer." 11

According to the New Zealand Suzuki Institute's website, today New Zealand boasts over 150 teachers with approximately 2,000 students nation-wide, ${ }^{12}$ and we are told by the Talent

\footnotetext{
8 Suzuki.org.nz. (n.d.). Dr Shinichi Suzuki. [online] Available at: http://suzuki.org.nz/ [Accessed 28 Jun. 2019].

${ }^{9}$ Suzukimethod.or.jp. (n.d.). The History of the "Talent Education Research Institute”. [online] Available at: https://www.suzukimethod.or.jp/english/E_mthd111.html [Accessed 28 Jun. 2019].

${ }^{10}$ Suzuki.org.nz. (n.d.). Dr Shinichi Suzuki.

${ }^{11}$ Ibid.

${ }^{12}$ Suzuki.org.nz. (n.d.). Suzuki in NZ. [online] Available at: http://suzuki.org.nz/ [Accessed 28 Jun. 2019].
} 
Education Research Institute's website that there are more than 400,000 children in 38 countries studying under Suzuki's philosophy. ${ }^{13}$

\section{The Philosophy}

The International Suzuki Association (founded in 1983) states that the Suzuki Method is "based on the principle that all children possess ability and that this ability can be developed and enhanced through a nurturing environment."14 Pedagogical tenets of the Suzuki philosophy listed on the International Suzuki Institution include: exposure from the start; listening with imitation; learning to play before learning to read; parental involvement; a nurturing and positive learning environment; the emphasis on producing a good sound (more important than aspects such as note-perfect playing, which complements Suzuki's life motto of "character first, ability second"); the core repertoire which is used around the globe; and the social interaction with other children, even those who do not share the same spoken language. ${ }^{15}$

Suzuki believed if any child was given the correct training that they could master music. Suzuki has created a philosophy and methodology which has shown that particularly young children have far more capacity than is expected. If the child, parents, and teacher can make the learning process fun, the child's musical abilities will develop to a very high standard. Not all of the Suzuki students will reach a world-class level of skill, but some of them do, and for those who do not reach the world stage, the hope is that music will bring them joy for the rest of their lives.

As Suzuki believed, "Every child is sure to grow and develop in the belief of their parents."16 When learning to speak their mother-tongue, children are not berated by their parents for a lack of fluency. A nurturing mother speaks to her child with a loving smile on her face and will do so from the birth of the child. The child can therefore easily grasp the language, as they have no inferiority complex about their abilities. This same principle can be applied to the teacher and pupil - no teacher should get angry or frustrated with their pupil due to a lack

\footnotetext{
${ }^{13}$ Suzukimethod.or.jp. (n.d.). The History of the "Talent Education Research Institute".

${ }^{14}$ Suzuki.org.nz. (n.d.). Dr Shinichi Suzuki.

15 Ibid.

${ }^{16}$ Suzuki Talent Education Program. (n.d.). Suzuki Program Information. [online] Available at: https://stepbrandon.weebly.com/about.html [Accessed 26 Jun. 2019].
} 
of competency but instead should encourage them to develop their own ability of the musical language.

Repetition is a very necessary part of the Suzuki Method. When learning to speak their language, a child constantly tries sounds and syllables and their ease of speaking develops through the repetition of these new sounds. Eventually they are able to form words, then sentences, then hold a conversation with someone with an advanced level of vocabulary and an in-depth understanding of what they and their conversing partner are saying. It is the same with music. The pupil constantly tries new sounds and becomes gradually more and more competent, understanding which notes they are making and playing them with good tone and technique. It is only through repetition that the child is able to reproduce these sounds.

When children first learn how to speak, they love to speak and they practise it every day. When connecting with older children, the younger children become conscious of the necessity of learning more and more words to aid them in their conversation and understanding. They desire to be better, and they are self-motivated to learn and develop their conversational ability. The same is true for music. When a child watches an advanced student playing higher level pieces on their instrument they are inspired and look forward to playing those pieces in a few years. The daily listening to recordings is also a very important part of a child's learning and can be directly correlated to the way a child learns to speak in their mother tongue.

The Suzuki Method also focuses on the community and family aspects of music. Suzuki students attend regular group lessons where they can add repetitions of the pieces they are learning while interacting with other students of a similar age and/or musical ability. The parents also get to know each other as they will stay at the group lessons with the children. These group classes and regular activities with their peers lead to an early involvement in chamber music and participation in orchestras or other ensembles, and the lessons also teach essential ensemble and listening skills. They also nurture the cooperation among students and supportiveness of one another's accomplishments, rather than the competition which is sometimes seen in some non-Suzuki musical environments. ${ }^{17}$

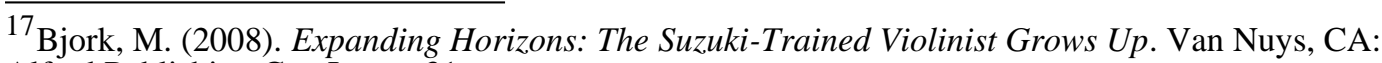
Alfred Publishing Co., Inc., p.31.
} 
The student's whole family will regularly attend camps and workshops throughout the year. At these workshops the children have lessons in small masterclasses, take part in group classes, and play in ensembles. These events are often the musical highlight of a Suzuki student's year and something students can work towards throughout the year. The wider Suzuki community is strengthened and often life-long friendships and musical connections are made at these events.

The early exposure to music is seen as unique to the Suzuki Method. Suzuki believed that education began at birth, as the child's brain is already developing and new connections are being formed and solidified from day one. "What [children] receive from their parents at the day of their birth is not language itself but the ability to learn and speak language, and provided the babies have no physical defect, all are born with these qualities." 18 This development is most noticeable when one considers the development of spoken language. "A child's vocabulary usually includes about 50 words at 18 months, 100 words at 20 months and 14,000 words at 6 years." 19 By the time they are two years old they are starting to piece together simple words such as 'mummy big' or 'baby crying'. With this ability, it is not surprising that children as young as three years old are able to learn the musical 'language' and develop a musical instinct from that early age.

Another important factor in a Suzuki student's musical development is that the teacher moves in small steps, and at the child's pace. This allows the child to easily and successfully master the new material, in turn building their sense of achievement and enthusiasm for learning. "It is a goal of Talent Education to make a child's ability 'his own' by giving him an environment in which he can develop his character to its full potential, regardless of how he plays the instrument." 20

The parent attends all of the lessons so that they have the ability and confidence to work with the child at home. Parental involvement is imperative in the learning process, and the ability will be developed through the "skillfulness with which the parents build up enthusiasm in the

\footnotetext{
${ }^{18}$ Landers, R. (1984). The Talent Education School of Shinichi Suzuki-An Analysis: The Application of Its Philosophy and Methods to All Areas of Instruction. New York: Exposition Press. p.7.

${ }^{19}$ Beaupré, L. (2010). Language: Your Baby's First Steps Toward Learning to Speak. [online] Child-encyclopedia.com. Available at: http://www.childencyclopedia.com/sites/default/files/docs/coups-oeil/language-info.pdf [Accessed 10 Feb. 2020].

${ }^{20}$ Bauman, S. (1994). In Search of the Japanese Spirit in Talent Education. New Jersey: Summy-Birchard. p.6.
} 
child, and the happiness the child finds in acquiring their new-found ability."21 Any child can learn his mother tongue, but it is clear that someone must be present to teach and help them to learn. This is also where the relationship with the teacher comes in, as the 'formal' training may start by age three.

${ }^{21}$ Barrett, C. (1995). The Magic of Matsumoto: The Suzuki Method of Education. California: ETC Publications. p.46. 


\section{Chapter Two: The Early Volumes}

\section{$\underline{\text { Suzuki Cello Volume One }}$}

As discussed in Chapter One, the Suzuki Method promotes a very early starting age and 'formal' musical training can begin at age 3. Children of that age need as much assistance as possible while learning a new instrument, as there are many complex ideas and skills to be learnt. One of the tools employed by Suzuki Cello Teachers in New Zealand is the foot chart: a large piece of thick cardboard on which are marked the position for the front legs of the child's small chair, the feet position while playing the cello (in green pen for 'go') and the position of the feet together for bowing (in red pen for 'stop'). The spike hole is also marked on the foot-chart and there is a mark drawn on the cello spike to show the length the spike should be. When the child has consistently demonstrated the correct position for their feet, the foot chart may be exchanged for an end-pin stopper which attaches to a leg of the chair and provides the basic position for the spike.

The first work in the Suzuki Cello Method is 'Twinkle, Twinkle, Little Star and Variations', commonly referred to by Suzuki teachers as the 'Twinkle Variations'. However, before the student is ready to start working on the 'Twinkle Variations', they must learn the following: a good sitting posture and correct cello positioning; the ability to focus; a well set-up bowhold; round fingers and a sense of heaviness in the arm to hold down the cello strings; a knowledge of the finger numbers and the ability to play D major scale tetrachords; lots of rhythm practice (primarily of the 'Variation' rhythms); pizzicato ringing sounds; and finally, how to draw the bow on the open strings of the cello.

Over a period of months or upwards of a year, the student begins to collate these techniques and can combine all of the different components that make up the 'Twinkle Variations' with the goal of playing all four variations and theme by themselves. Once the fingering has been internalised well and the rhythms have been mastered on open D and A strings, the teacher knows that the student is ready to play the 'Twinkle Variations'.

'Twinkle, Twinkle, Little Star and Variations' is a set of four variations on the children's song 'Twinkle, Twinkle, Little Star'. This is the first 'proper' work that the student will learn and it is quite long, at approximately three minutes in length. Consistent with the philosophy 
of the Suzuki method, the student learns at their own pace and progresses as they are ready. Therefore, the student should be adequately prepared with all of the appropriate rhythms and techniques needed to play through this piece. This piece includes the D major tetrachords which are interspersed between open strings and provide an opportunity for repetition and consolidation. Although there are four variations to the theme, many teachers make up variations to teach a new bowing technique. These will be mentioned at various points in the thesis.

Having mastered the D-string tetrachord in "Twinkle, Twinkle, Little Star," the student can progress to the second piece in Suzuki Cello Book One, which is 'French Folk Song'. This work also introduces a descending D major scale, a concept which the student can easily grasp as they now have the knowledge of tetrachords. It is the first of three pieces in Volume One for cello that are not included in the violin books.

The folk song 'Lightly Row' follows 'French Folk Song'. This work introduces the interval of a third; previously the motion has been 'stepwise', with consecutive notes. This piece also introduces a new 'form' as the first two phrases are very similar with different endings, and the fourth phrase is a direct repetition of the second phrase. In a simple explanation, the form is "A A1 B A1". The bowing pattern in this piece is what some teachers call 'alternate bowing' - a long bow followed by two bows at the tip, then a second long bow followed by two bows at the frog.

'Song of the Wind', another folk song, introduces the continuous staccato bow stroke, which is developed from the short bows in the 'Twinkle Variations'. This continuous bow stroke is further refined in pieces later in the volume such as 'Perpetual Motion' and 'Etude'. 'Song of the Wind' also includes bow retakes (called "bow circles" by most Suzuki teachers), which develops the student's instinctiveness to starting phrases with a down-bow.

The fifth piece in Volume One is 'Go Tell Aunt Rhody'. This folk song demonstrates different rhythms which the student has not come across before. Most Suzuki teachers put words to a selection of the pieces, and 'Go Tell Aunt Rhody' greatly benefits from the use of this teaching tool. Some teachers have lyrics, while others use a specific word for each note length so that the bowing pattern is clear. Whatever method the teacher uses, the student is able to master the piece much more quickly if they can sing the tune with words. 
This piece also introduces small bows (up to a quarter of the bow) at the tip, which is quite a difficult cello technique for a beginner to learn as the point of contact is so far from the hand. It requires a good bow hold and pronation of the wrist. By the time the student reaches this piece, they should have a reasonably stable bow-hold and can imitate what the teacher shows them. The bowing technique of a long bow followed by two little bows will be referred to as 'alternate bowing' as the next piece has small bows alternate between the frog and the tip.

'O Come Little Children' further develops the bowing techniques learnt in 'Go Tell Aunt Rhody', with the alternate bowing at the frog and the tip. There are four phrases in this folk song; however, the bowing pattern of the first phrase is repeated in the following three phrases.

There is an added challenge of up-bows. Until this point in the book, the student started every piece with a down-bow at the frog. 'O Come Little Children' starts with an anacrusis and the student must start the bow at the balance point. Many teachers put a sticker on the bow as a visual reminder of where to start the bow. The challenge of the anacrusis is made more challenging by the fact that each phrase also finishes with an up-bow. The student must stop the bow after each phrase and leave enough bow to continue with the following phrase. This is where the sticker is useful as a visual reminder and as positive reinforcement. This piece also includes the top two notes of the D major arpeggio: the open A string and the fourth finger playing a D on the A string, which helps to prepare the student for 'May Song'.

The final folk song in Volume One is 'May Song'. This short piece starts with a four-note D major arpeggio. As the student has mastered 'O Come Little Children', which introduces the top two notes, and 'Lightly Row', which includes the bottom three notes, the student can easily learn this arpeggio. The only new technique to learn in this piece is the dotted rhythm, which is made slightly more challenging by the string crossing in the middle of the first bar. Ideally the student will learn the dotted rhythm first, then add the notes once they understand this concept. This is one example of a new 'twinkle variation' - the rhythm from the first bar of 'May Song' may be used as a practice rhythm.

'Allegro' by S. Suzuki is the eighth piece in Suzuki Cello Volume One. It is very energetic and for the first time has contrasting characters, with a phrase marked dolce between the 
outer, more boisterous phrases. The bowing is martelé; long and fast stopped bows which will have been introduced (at a very basic level) in the theme of 'Twinkle Twinkle Little Star'. There are some performance directions in the score, such as the fermata, rit., and a tempo. The bow circles from 'Song of the Wind' are included at the end of each phrase.

Following the energetic 'Allegro', S. Suzuki's 'Perpetual Motion and Variation' is the ninth piece and is effectively a study piece. It is the first of many sequential exercises and has three distinct sections, the first being repeated as the fourth section. The bow stroke for 'Perpetual Motion' is the same as for 'Song of the Wind'. The variation has each note from the original theme played two times in the space of one, and with a shorter bow stroke. No new bowing or fingering is taught, however the relentless quavers can pose a challenge for the young student. This is an important piece to listen to, as the student is more instinctive and will learn the notes faster if they know how the piece should sound.

'Perpetual Motion' is also included in this book in the key of $G$ major as preparation for the following group of pieces, and the student is instructed to "transpose all previous pieces to the key of $\mathrm{G}$ major in preparation for 'Long, Long Ago'.,22

After 'Perpetual Motion' there is a tonalisation exercise. This consists of a $\mathrm{G}$ major arpeggio of one octave, and a C major arpeggio in second inversion, again one octave. The student is instructed to "always strive for a more beautiful and resonant tone" 23 when playing this tonalisation. The tonalisation also includes the five 'ringing notes' which can be found in first position. 'Ringing notes' are termed such because when played in tune, the sympathetic vibration of the corresponding open string causes a 'ring'. There is also a G major scale; the D major scale was included at the start of the book as an introduction to the first position. Suzuki believed that a student must learn tonalisation in order to properly reproduce and perform music. ${ }^{24}$

Having reached Bayly's 'Long, Long Ago, the student is now at the point in the volume where they are learning a piece on the $\mathrm{G}$ string, and they also have their first $\mathrm{C}$ string note. The angle of the bow should be changing from being angled to the A string to being angled to the $\mathrm{C}$ string so the bow is parallel to the bridge and perpendicular to the string. This advanced

\footnotetext{
${ }^{22}$ Suzuki, S. (1982) Suzuki Cello School, Volume 1: Cello Part: Revised Edition. . Miami, FL: SummyBirchard, Inc.. p.14.

23 Ibid., p. 15 .

${ }^{24}$ Lavie, K. (2005). "On Gastronomy and Tonalization." New Zealand Suzuki Journal 16(4), p. 5-6.
} 
technique is introduced as a concept at this point in time but becomes more important in later pieces. The thicker $\mathrm{C}$ and $\mathrm{G}$ strings need more arm weight in order to produce the deeper, connected sound. 'Long, Long Ago' revises alternate bowing (with slightly less bow than on the A string) and the bow circle. The compositional form of this piece is the same as 'Lightly Row', with a different ending in the second and fourth phrases (“A A1 B A1").

S. Suzuki's 'Allegretto' continues to develop the student's tone on the G and C strings and continues the alternate bowing with the emphasis on the third note of each pattern (the downbeat, as there is an anacrusis of two quavers). This contrasts with the following piece, 'Andantino'. There is not anything unexpected or unseen for the student, as the form of this piece is identical to 'Long, Long Ago,' and the bow circle is also included.

'Andantino', again by Suzuki, is very similar to 'Allegretto' however there are a few minor differences which are necessary to point out. The first is the rhythm; the pattern of two quavers and a crotchet is the same, however in 'Allegretto' the emphasis was on the third note of each pattern (after the anacrusis) and in 'Andantino' the emphasis is on the first note of each pattern, which is also the down-beat. This difference must be explained and demonstrated carefully to the student.

The following piece in Volume One is Purcell's 'Rigadoon'. This is the second of the three pieces for cello which are not included in the violin books. The form of this piece is identical to 'Perpetual Motion', with three clear and obvious sections, and the first section is repeated as the fourth section. There is one new concept that the student has not yet come across, and that is the use of the second finger. In 'Rigadoon' the second finger is only used on the A string in place of the third finger, and on the D string only the third finger is used. This is a clear and understandable instruction for the student and should not cause much confusion, although mistakes will be made as the student adjusts to the use of the second finger in place of the third.

The bowing in this piece is also a challenge. The piece includes the bow circles at the end of most phrases, and there is alternate bowing in the middle two sections of the piece The new bowing challenge is in the second bar, where the student plays a dotted minim followed by a crotchet. They must save their bow for the dotted minim and aim to get back to the frog in the crotchet. The most important thing for the student to focus on is the bow conservation on the 
dotted minim, so that they do not travel too far out in the bow. There are also two different endings for each of the sections, and the student must be familiar with how the piece sounds in order to memorise this piece quickly. This piece may take longer to learn than the previous few pieces due to the new or altered ideas and techniques present. In accordance with the Suzuki philosophy, the student will progress through this piece at their own pace and gradually master the techniques necessary to perform it.

S. Suzuki's 'Etude and Variation' is the piece that follows 'Rigadoon', and as its French title tells us, this piece is a study. As in 'Perpetual Motion', there are relentless quavers throughout the whole piece which can pose a challenge for the young student. This piece is an important piece to listen to so that the student is more instinctive and knows when they are correct or incorrect. The piece explores the $\mathrm{C}$ major scale using all the notes in first position, therefore continuing the use of the second finger on the A string and also substituting it on the D string. The bow has the same stroke as 'Perpetual Motion', with the student playing close to the frog to achieve a good, rich tone. There are many complex finger patterns throughout this piece, and the student will be given 'box bars' (passages which need extra practice or attention) to single out and practise at home. This piece is a good lesson in repetition and the variation, following the same principle as the variation for 'Perpetual Motion', helps this repetition.

'The Happy Farmer' by R. Schumann is the fifteenth piece in Volume One, and it introduces a few new techniques and ideas. The first of these is the hooked bows and dotted rhythm in bar 1. The hooked bowing is something that the student will not have come across before, and to help teach this bowing many teachers will put stickers on the bow in the appropriate places so that the student knows where to stop the bow each time. Repetition is the most efficient way to learn this piece, and it is recommended to apply this bowing across to familiar aspects of the student's playing, such as scales or in a new Twinkle variation, so that the student has an external source of practice for the bowing. Once the student is confident with the bowing they may then try with the notes in bar 1, however they must be aware of the string crossings that occur in the middle of the pattern.

There are also a few bow retakes in this piece, however this time the student retakes to the balance point in order to play another up-bow. There are a few challenging passages which need repetition with some difficult finger work that need careful practice. The last challenge is remembering the form of the piece, which is different to anything the student has come 
across. The first phrase is repeated, then there is a new section followed by an altered version of the first phrase, both of which are repeated. This can be written as "A A B A1 B A1"

'Minuet in C' by J.S. Bach is the penultimate piece in Suzuki Volume One. It is the first minuet that the student learns and contains a new bowing pattern which is commonly referred to as "Minuet Bowing": a crotchet down bow (of approximately two-thirds of a bow) on the downbeat, followed by two lighter hooked up-bow crotchets of equal length. This bowing can be rehearsed using scales and an invented Twinkle variation until the student has mastered it.

This piece also modulates from $\mathrm{C}$ major to $\mathrm{G}$ major, and the student must recognise when to use the third finger and when to use the second finger. This can cause confusion, but if the teacher perseveres the student will understand in their own time. 'Minuet in C' is a Baroque piece, and it needs a light and graceful tone with a good sense of phrasing and direction.

The final piece in Suzuki Volume One is J.S. Bach's 'Minuet No. 2'. This minuet continues the learning from 'Minuet in C'. The new techniques that the student is learning include slurred triplets and a forward extension. The extension is only for one note and involves moving the hand one semitone up the cello. At this point the student is learning where the new note is, and they are not concerned with the technique behind an extension. This will be revisited in 'Witches Dance' which is seen halfway through Volume Two.

\section{$\underline{\text { Suzuki Cello Volume Two }}$}

The first piece in Suzuki Cello Volume Two is Bayly's 'Long Long Ago and Variation'. The student has already played this piece in Volume One, however this version is in a different key and the student must learn a different fingering. The Variation introduces a new bowing, which is a two-quaver slur followed by two quaver up-bows. This bowing can be practised on 'Perpetual Motion', 'Etude', and made-up twinkle variations.

'May Time' by Mozart is the second piece in Volume Two, and the last piece (with the exception of optional shifting in 'Berceuse') to use solely first position. It introduces the concept of compound time, and hooked bows in 6/8 time, rather than the common 4/4 time as seen in 'The Happy Farmer'. The piece reviews the $\mathrm{C}$ major arpeggio and slurred triplets first seen in 'Minuet No. 2', the last piece in Volume One. It also reinforces modulating from C to 
G major, and the appropriate second/third finger use. This should now be well understood by the student and will be included in most of the new pieces they will learn.

The third piece in this volume is 'Minuet No. 1' by J.S. Bach. This is an important piece as it is the first to introduce shifting and position work. The student will begin using second position and will spend the rest of Volume Two solidifying this technique while committing the position to muscle memory. From this piece until the end of Volume Three the positions are indicated below the cello part, shown as "2nd pos." with a bracket to indicate how long the student stays in this position. 25

'Minuet No. 3' by J.S. Bach is the fourth minuet that the student learns. There are many passages in second position, and two of these contain backward extensions. The student must practise this distance and remember how far to stretch their first finger. This piece also introduces shifting from a fingered note rather than from the open string. The piece gives the student the opportunity to solidify baroque-style playing through having lighter second and third beats and creating clear phrase shapes. As with the rest of the volume, the piece also focuses on position work with particular emphasis on the extended second position.

"Chorus from "Judas Maccabeus"' by Handel is the fifth piece in Volume Two. It is a slow piece which focuses on full, legato bows and good tone. The new bowing aspect is that there are now four notes in a slur. This piece introduces the use of the third finger ( $G$ sharp) in second position but does not include any extensions.

The sixth piece in Volume Two is the energetic 'Hunters' Chorus' by von Weber. The focus of the piece is the bowing, as there is no new material in the left hand. There are four notes in a slur, and while this has been introduced in 'Chorus from Judas Maccabeus' the slurs in 'Hunters' Chorus' are faster and contain string crossings. The piece requires good coordination, so the student should be doing regular exercises for finger dexterity, with scales or other similar exercises such as those found in Piatti's "Violoncello-Schule" books.

'Musette from English Suite No.3' by J. S. Bach is the next piece in the volume and, in contrast to 'Hunters' Chorus', uses a lighter bow stroke similar to the minuet. Some extra

\footnotetext{
${ }^{25}$ Suzuki, Dr, S. (1992) Suzuki Cello School, Volume 2: Cello Part: Revised Edition. . Miami, FL: SummyBirchard, Inc.. p.8.
} 
bow techniques are included, such as the phrase ending with decrescendo on an up-bow which is counter-intuitive. The left-hand technique to learn is the contraction shift, which moves the hand from one position to another by contracting then expanding the hand rather than shifting the whole hand all at once.

'March in G' by J. S. Bach follows 'Musette' and is the first piece in a march style. This baroque piece differs from previous pieces in that the bowing and character is clean, clear, and energetic. The phrase endings are tapered, and the student must vary the bow speed so that the first of the two notes has more bow and the second has less. There are many dynamic markings of which the student should be aware. Syncopation is also introduced not as a teaching point but rather as a single, uncomplicated bar. This is the first piece in the cello volumes to introduce 'optional fingering', with three shifts to second position bracketed underneath the score.

Paganini's 'Theme from "Witches' Dance"' is the next work and introduces the fast hooked bow. The student will be familiar with this concept, from 'The Happy Farmer', but the faster speed of the bow in this piece makes this technique more challenging. There are accented upbows which the student has not come across yet, and the extended fourth finger seen in 'Minuet No.2'. The student must learn arpeggios in second position and must be able to land in extended second position from an open string. There is also a backwards extension in first position; until this point it has been only in second position. This is the largest stretch the student does until the professional repertoire where they may choose to add larger extensions.

'Moon over the Ruined Castle' by Taki is a tonalisation piece which focuses on the production of beautiful tone and consolidates the backward extension in first position. This piece is repeated in Volume Three in different keys and positions.

'The Two Grenadiers' by R. Schumann is the first piece with a written piano introduction and the student must know when their part begins. The new bowing in this piece is the quick bow retake for two down-bows. The hooked bow is also revisited, but this time it is interspersed with various other bowings and note values, so the student must be very conscious of each rhythm. The performance of this piece is improved if the student uses extreme contrasts in character. The only previous piece with a similar character dichotomy to this is 'Allegro' in Volume One. 
The penultimate piece in Volume Two is 'Gavotte' by Gossec. Like the minuet and musette, this is a dance that was very popular in the eighteenth century. Dances of this type seem to be well-suited to teaching fundamental cello techniques, as the playing style is clean and articulated. 'Gavotte' introduces grace notes to the student, and as Kara Eubanks said of this piece in her recent thesis, "the grace note is the trilling motion in its simplest form: velocity without continuation." 26 The grace notes in 'Gavotte' begin to prepare the student for trills which occur in the next volume. This piece is the first in which the student must use pizzicato as a performance technique rather than a practice technique to aid in note-learning, and it contains the first forward extensions from a fingered note.

The two other techniques that the piece covers are broken octaves and very fast slurred semiquavers. The broken octaves can be discussed as "ringing notes", and the fast semiquavers require much slow repetition to coordinate the fingers, bow change, and string crossing. At nearly three minutes in length, this is the longest piece that the student has played. The student needs stamina and concentration in order to get through the whole piece - there are four quite different sections and they must be able to remember the order in which they are played and repeated.

'Bourrée' by Handel is another eighteenth century dance and continues the baroque style of playing. The extended second position is solidified and there is much sequencing throughout the piece. There are a few challenging bowing patterns that the student must figure out and some places where bow conservation is necessary, but this is a consolidation piece for Volume Two and there are no new techniques to learn in it.

Volume Two covers a range of bowing techniques while allowing the student to become confident and familiar with shifting to second position. Depending on the age and abilities of each student, Volume Two is a suitable place for the student to begin formal work on reading in bass clef and the Suzuki teacher should be encouraging this. There are many different materials which may be used, however the Suzuki books do not recommend anything specific and materials chosen are at the teacher's discretion.

\footnotetext{
${ }^{26}$ Eubanks, K. (2015). Essays in the Theory and Practice of the Suzuki Method. D.M.A. City University of New York. p.114
} 


\section{Chapter Three: Getting to Know the Positions and Techniques}

\section{$\underline{\text { Suzuki Cello Volume Three }}$}

'Berceuse' by Schubert is the first piece in Volume Three and it is considered a 'tonalisation' piece, focusing on good tone and sound and smooth bow changes. This piece gives an optional introduction to fourth position in the penultimate phrase, with the fingering bracketed underneath the stave. It is also the first piece to use the "halfway harmonic", the harmonic that is halfway between the nut and the bridge. By this piece the teacher may have briefly touched on the concept of vibrato, especially if the student is aware of and interested in the technique.

Following 'Berceuse' is a second version of Taki's tonalisation piece 'Moon Over the Ruined Castle'. The new version of this tonalisation introduces third position to the student while keeping the notes identical.

The second piece in Volume Three is 'Gavotte' by Lully. This piece introduces D minor scales, and as the student has not yet come across a minor scale in the repertoire, this is a major teaching point for 'Gavotte'. The harmonic minor scale includes an augmented second which requires an extension from the first finger to the third finger. This is a new finger pattern; however, the concept of the extension has been seen throughout Volume Two. The fourth finger extension is revised, and third position is used. This piece also introduces a semitone trill between the first and second fingers, with a static end rather than continuing into a nachschlag.

Another aspect of this piece is the bowing and articulation. The articulations are varied; the opening passage demands staccato and legato bow strokes, and the second section contains many slurs as well as the legato bows. The long piece requires the student to remember contrasting sections and the musical form.

After learning 'Gavotte' the student begins another minuet. 'Minuet' by Boccherini is a lighthearted piece with a corresponding Trio section and follows the traditional ternary form of 'Minuet-Trio-Minuet'. Using only the previously studied first and second positions, this piece revises forward extensions and the extension between first and third fingers seen in 'Gavotte'. 
Again, there are many different bowings to remember throughout the piece. The student covered many bowing patterns throughout Volume Two which all need to be consolidated. This will be very common in Volume Three and beyond and will not be mentioned again unless the patterns are new or exceptional. The trill is also re-visited, this time as a tone trill using the first and third fingers, and instead of a static end to the trill, this piece uses the nachschlag ending.

The two unfamiliar aspects of this piece are the syncopated rhythm and the accompaniment incorporated into the student's part. Although there are a few places in which syncopation happens, each syncopation lasts for only a bar, therefore the student should not have a problem with learning this. When the piano accompaniment takes the tune in two 4-bar phrases, the passage in the student's part can be difficult to memorise as the two phrases end differently; one includes syncopation, the other simply finishes before the syncopation.

The piece that follows 'Minuet' is the volume's second 'Moon Over the Ruined Castle', and this time the tonalisation piece formally introduces fourth position. In order for 'Moon Over the Ruined Castle' to be played in fourth position, it is transposed up a major sixth from the original first seen in Volume Two. The student knows how the piece sounds and can work out the notes easily for this work.

The fourth piece in Volume Three is 'Scherzo' by Webster. This is a fast piece with relentless semiquavers and fast position changes in the opening section. 'Scherzo' revises the scherzo and trio form first seen in Allegro from Volume One. The semiquavers in the opening can tire the student, but this bowing pattern is familiar from Perpetual Motion in Volume One. The contrasting 'meno mosso' section is much slower in note values, requiring very smooth bows, and the tempo may relax slightly. This piece revises extended second and fourth position, and the last two bars introduce the quarterway harmonic* found in first position.

Following 'Scherzo' is Beethoven's 'Minuet in G', which is again in the form of minuet and trio. The minuet focuses on the dotted rhythm. There is a very fast four-note slur with a shift in the middle which requires coordination and anticipation. Closed fifth position (where the semitone is between the first and second fingers and the tone between the second and third) is

*Lightly touch the finger a perfect fourth above the open string. The note produced is two octaves above the fundamental. 
introduced in the minuet, and in the trio the student must learn half position. The trio also introduces the up-bow staccato with either three or four rearticulated notes in each up-bow.

'Gavotte in C minor' by J.S. Bach is a piece focusing on extensions and tone. The bowing is occasionally non-instinctive but has been previously studied in other pieces. Lower second position is introduced, as is the lower extension to fourth position. This piece also introduces finger swapping, which is when one note is repeated a second time but played with a different finger. 'Gavotte in C minor' is in rondo form, with the first eight bars repeated between the subsequent sections. The student must be familiar with $\mathrm{C}$ minor scales (the natural and melodic minor scales are included in the volume and appear directly before 'Gavotte in C minor') as this piece contains many segments of the natural and melodic minor scales; the third section modulates to $\mathrm{G}$ minor before returning to the $\mathrm{C}$ minor opening section to finish.

The seventh piece in Volume Three is 'Minuet No. 3' by J.S. Bach. Although 'Minuet No. 3' was studied in Volume Two, this version includes a section in $\mathrm{C}$ minor which contrasts with the opening key of $\mathrm{C}$ major. The minor section focuses on learning lower second position after its brief introduction in the previous piece, 'Gavotte', and there are many position changes to and from lower second position, as well as second, third, and fourth positions.

After 'Minuet No. 3' is 'Humoresque' by Dvořák. This work has three different sections, with the first section is alternated with a different section throughout the whole piece. The first section has a rhythm very similar to Beethoven's 'Minuet in G', however this rhythm has a rest rather than a dot which makes the sound lighter; leggiero is the performance direction. This piece continues to familiarise the student with second, third, fourth, and fifth positions, and added to this is seventh position. This is quite a high note, a minor third above the halfway harmonic, and the student must have the appropriate left-arm position in order to comfortably reach this position. This is the highest position the student learns until they reach Volume Six, and seventh position is only revised in Volume Five.

The penultimate piece in Volume Three is 'La Cinquantaine' by Marie. At three pages in total this is a very long piece with a few different sections, some of which are repeated and some of which are not. 'La Cinquantaine' reintroduces the grace notes seen in 'Gavotte' by Gossec, however instead of a single note, this piece has two notes to fit in before the beat. The piece also revises the trills first seen in 'Gavotte' by Lully, this time with both a semitone trill and a tone trill. There is one new position; upper third position. The new bowing in this piece is 
portato - four notes to a bow with a tenuto marking on each note, so the student must rearticulate each note without inadvertently making them staccato notes.

'Allegro Moderato' by J.S. Bach is the final piece in Volume Three. Similar to 'The Two Grenadiers', this piece begins with an introduction from the piano and the student must know when to come in. A new bowing taught in this piece is as follows: one note followed by three slurred notes, with the pattern repeated consecutively six times. This requires consideration of bow distribution and conservation. The student may remember a similar albeit slower pattern in 'Rigadoon', when the first three beats of the bar were played using one down bow and the last beat was played using the up bow. 'Allegro Moderato' also includes syncopation, which was first seen in 'Minuet' by Boccherini. However, the syncopation in this piece is different in that the syncopated bars alternate with the regular, metrically accented bars for approximately ten bars.

By the time the student reaches the end of Volume Three, they should be proficient in the use of most second positions and all third positions, the lower extension and closed fourth position, and closed fifth position. They will have had an introduction to seventh position and will be familiar with the area around the halfway harmonic. At the rear of Volume Three is a list of scales, and the student should be working on these for the duration of the volume as these coincide with the positions covered in the volume. The student will have an understanding of trills, most rhythms, and a variety of bowing patterns. While there is only one piece that uses the $\mathrm{C}$ string (this volume primarily explores the higher positions), the student should have a secure knowledge of the notes on the cello ranging from the lowest notes up to the halfway harmonic. As mentioned in Volume Two, this is the last book in which positions are indicated underneath the cello part, and from Volume Four only the fingering is given so the student learns to recognise which position applies to the suggested fingering.

\section{$\underline{\text { Suzuki Cello Volume Four }}$}

Volume Four begins with 'Sonata in C major, Op. 40 No. 1', by the Classical composer Bréval. This is the first sonata in the volumes and the first piece to have two movements. The first movement, 'Allegro', begins with three chords triple or quadruple stops. This is the first time the student has used chords, and there are double stops later in the movement. 
There is one unfamiliar rhythm; a semiquaver followed by a dotted quaver. Although this rhythm was seen in 'Humoresque', it is much faster in this piece and the student must avoid playing the semiquaver as a grace note before the beat. There is also a specific left-hand technique that the student has seen only once before in Volume Two, and that is the contraction shift. The left hand moves between consecutive positions by contracting and then expanding rather than the whole hand shifting in one motion.

Another new aspect in this piece is the consecutive string crossings. In the first of these string crossings, the student must play the G-string followed by the A-string, and also the C-string followed by the D-string, missing the middle string each time. This happens eight times in a row and involves large arm movements between lower and higher strings and a flexible bow hold. The second string crossing section is easier in that the student does not have to avoid the middle string, however the left-hand finger pattern is more challenging than the first.

The final new feature to this movement is the form of the piece. This is the first work in sonata form and the piece is very long with subtle but necessary differences between the exposition and recapitulation sections. The student must remember which phrase ending to play in order to continue to the correct section of the piece.

The second movement of Bréval's sonata, titled 'Rondo Grazioso', is the first piece since 'May Time' in Volume Two to be in 6/8 time. Written in rondo form, this piece has a few different sections, second and fourth positions to revise, and many notes to learn in this piece including some fast scalic passages which the student does not have much experience with.

Following the sonata by Bréval are the first two of four movements from Marcello's 'Sonata in E minor, Op. 1 No. 2'. These movements are titled 'Adagio' and 'Allegro'. The short and concise first movement, 'Adagio', has many position changes and a passage focusing on finger swapping, a technique which was first seen in 'Gavotte in $\mathrm{C}$ minor'. The bowing is relatively straightforward, but the student must have a very controlled bow, knowledge of bow division, and a sense of the appropriate amount of bow to use.

The second movement of the sonata, 'Allegro', is a fast piece with many semiquavers and fast position changes. Typical to Baroque music, this piece should be played with detached quavers and smooth semiquavers, and this piece gives the student the opportunity to practise 
this. Due to the length and speed of the piece, there are many notes to learn in this piece, however the many scales and sequences throughout assist with memorisation.

To continue the baroque theme, the third set of pieces in Volume Four is J. S. Bach's 'Minuets I \& II from Suite No. 1 in G major, BWV 1007'. These minuets are taken from the first of Bach's six cello suites and are the first of the suites that the student plays. The first minuet focuses on smooth slurred string crossings or broken chords, but it is more about revising the style than learning new techniques. The second minuet is in $\mathrm{G}$ minor, and intonation is a major focus because of the tonality and accidentals. There are many diminished arpeggios and extensions, both of which are challenging to play in tune.

The last piece in Volume Four is a transcription of the piano piece 'Chanson Triste' by Tchaikovsky. This is the first late Romantic piece the student plays, as the majority of previous pieces in the volumes have been baroque, and it requires a rich and singing tone. There is much position work, and sixth position is introduced for the first time in this piece. There are also four shifts on consecutive notes which has not been seen before, and this is difficult to execute cleanly.

The dynamics and phrasing throughout this piece are key factors in a polished performance. Musicologist Jim Samson said that Classical composers are "more interested in the formal structure of music" whereas Romantic composers focus on "free, untrammelled expression." 27 In order to get the dynamic contrast and phrasing that this piece requires, the student must have complete bow control and follow the dynamics printed in the score.

'Chanson Triste' also introduces the tenor clef. Cellists are expected to read three clefs, and until now the student has been playing pieces entirely in bass clef. By the end of Volume Four, the student will have some understanding of tenor clef, and after playing the pieces in Volume Five, of which a good proportion are in tenor clef, the student will be a much more fluent reader.

It is interesting to note that there are a number of pieces in the cello volumes which were not originally written for the cello. The earlier volumes contain many folk songs and common

\footnotetext{
${ }^{27}$ Samson, J. (2001). Romanticism. [online] Grove Music Online. Available at: https://www.oxfordmusiconline.com [Accessed 12 Aug. 2019].
} 
tunes (such as the Bach minuets and Suzuki's own compositions) which are played on many different instruments, but by the time the student reaches Volume Four, the pieces are all unique to the Suzuki Cello Repertoire and not shared by other instruments' method books. Many of the pieces selected for the cello volumes were popular at the time of developing the volumes and it was for this reason, as well as the technical benefits, that they were chosen over other similar yet lesser-known works.

On completing Volume Four the student should be proficient in shifting to and from most positions up to seventh position. The double-page of scales at the end of Volume Four reflect the knowledge of these positions, as these scales use all positions below the halfway harmonic. There is also an exercise in reading the tenor clef, which gives the impression that the student should have started formal training on tenor clef by the end of the volume (again depending on their age and abilities). The student now has the skills required to play chords and fast semiquaver passages, and they continue to be trained in the Baroque style, particularly with the bowing, phrasing, and dynamic contrasts. 


\section{Chapter Four: Consolidating the Positions and Techniques}

\section{$\underline{\text { Suzuki Cello Volume Five }}$}

The first work in Volume Five is the 'Sonata in E minor, Op. 14, No. 5', by Vivaldi. This sonata is in four movements, the first movement written entirely in tenor clef which continues to develop the student's understanding of the clef. There are a lot of position changes in this piece, and at this level the student should be competent at shifting between all positions. However, this work introduces both extended and upper fourth position to the student, both of which have not been used before. Although higher positions have been taught previously, upper fourth position is in a part of the cello that is more awkward as the little finger must be carried by the elbow and forearm around the shoulder of the cello. In higher positions (after upper fourth position) the fourth finger is rarely used, so the reach of the hand is not as great.

The second movement of this sonata is a quick 'Allegro', and is more challenging than 'Allegro' by Marcello in Volume Four, as there are more passages with continuous semiquavers and more passages that are arpeggiated. There are many string crossings which resemble those in the first movement of Bréval's Sonata in $\mathrm{C}$ major. There are also a few subtleties which the student must be aware of such as the slightly different endings of the main theme.

To follow the custom of slow, fast, slow, and fast movements, the third movement of the sonata is again a slow movement. Given the title of 'Largo', the piece is in a slow 12/8. This is a time signature the student has not yet seen in the Volumes. The piece introduces a new rhythm in the first bar; one dotted quaver, two demisemiquavers, and a quaver, all in a slur. This requires refined bow control as the demisemiquavers require a faster bow than the quavers in order to sound clearly and cleanly. This movement also requires slurred string crossings from the A to $\mathrm{G}$ string and $\mathrm{D}$ to $\mathrm{C}$ string, which involves missing one string and playing the next in a slur which adds another level of difficulty to the technique.

The final movement in Vivaldi's Sonata is a second 'Allegro'. This is in 3/8 time, which again has not yet been seen in the Volumes, and it is a quick piece with fast shifts, sometimes between much higher or lower positions. The bowing throughout the piece is a quick version 
of the 'minuet bowing' taught in Volume One. There is also syncopation in this work, and a lot of position revision. Upper fourth, a position rarely seen in the Volumes, is used again.

'Danse Rustique', Op. 20 No. 5, is a short miniature piece dating from 1895 . Written by the cellist Squire, it was one of the most performed works by Squire at the time. ${ }^{28}$ The piece starts with a four-bar piano introduction, and is only the third to have a written introduction (although the piano accompanists will often play the final few bars of the piece so that the student knows where to start). The title translates to 'Rustic Dance' and requires a chunky and energetic sound. It is quite a virtuosic piece, requiring quick thinking in transitions between sections. The work has a contrasting middle section which is marked legato, and the student must use bow conservation throughout the long phrases and held notes.

This piece also introduces the first fully fingered four-note chords (chords with no open strings). This is very challenging as the student must adjust their handshape to fit the curve of the cello's neck and to also find out where the perfect intonation is for their cello, as each cello is slightly different in regards to perfect fifths according to the plane of the fingerboard.

J.S. Bach's very popular 'Arioso' was arranged for cello and piano from the cantata Ich steh mit einem Fuß im Grabe, BWV 156. It is a slow baroque piece with dynamics that follow the phrase shaping and many scalic and arpeggiated passages. There are many shifts that need to be executed smoothly and a few large leaps, with intervals of sixths and a tenth. The student plays an open string then must play in seventh position with no guiding shift to help them.

The final piece in Volume Five is 'Rondo from Concerto Op. 65 No. 4', and the piece is a condensed version of the final movement of the concerto by Goltermann. The original version is approximately twice as long as the Suzuki version. With the exception of the twelve-bar introduction, the Suzuki edition omits the first half of the movement and the cello plays from the return of the opening theme. Although the thematic material is very similar, the omitted section is more difficult and slightly higher in pitch (it briefly uses thumb position) and has a more challenging bow stroke consisting of one quaver followed by five slurred quavers.

\footnotetext{
${ }^{28}$ Edition Silvertrust (n.d.). William Henry Squire: Danse Rustique for Cello and Piano, Op.20 No.5. [online] Editionsilvertrust.com. Available at: http://www.editionsilvertrust.com/squire-danse-rustique.htm [Accessed 1 Oct. 2019].
} 
The piece starts with a section that resembles 'Humoresque' from Volume Three, with dotted rhythm and a very similar bowing pattern with the added marcato technique at the tip. Phrases occasionally end with a diminuendo which is made more difficult due to finishing the phrase on an up-bow. Overall the student must know where in the bow they should be playing as the pattern alternates between slurs, marcato at the tip, and gradual transitions from the tip to the frog. There are quick shifts to and from the same finger within the same bow stroke, and the shifting technique must be light and almost inaudible.

The second section consists of descending scalic passages starting from the high B in sixth position before the music moves to a section with the performance direction molto grazioso (very gracefully). This requires a slow, controlled bow as there are many notes to fit in and phrasing to be aware of. A faster section, a tempo, follows this, again with lots of triplet scales and contrasting bow strokes from smooth to staccato when each scale is repeated. This is the fastest that the student has played using a staccato bow, and they must practice their control of the detached sound.

One new technique that the student learns in this piece is ascending and descending arpeggiated chords. Although the student has not come across this specific technique before, they have had preparation for this in Volume Four and early Volume Five, with the consecutive string crossings in the first movement of Bréval's 'Sonata in C major' (Volume Four) and the second movement of Vivaldi's 'Sonata in E minor' (Volume Five). The arpeggiated chords in 'Rondo' require a similar bow technique with the addition of an extra middle note and the control to play the top note twice.

The last section of the work is given the performance direction of animato and continues to use the bowing in the previously mentioned broken chords for fifteen consecutive bars. The piece then introduces another new bowing in the form of three slurred notes followed by three separate notes. The student must consider their bow division for this. The piece finishes in a flurry of fast scales and arpeggios before a chordal seven-bar perfect cadence.

Volume Five continues to solidify the positions covered in the previous books and, as well as a continuation of the Baroque style, this volume focuses on the Romantic style with two late Romantic works. The student will be confident in both fast and slow pieces from a range of styles and the positions and finger patterns below the harmonic should be well-understood. 
The page at the back of the book aids in this knowledge with two exercises: 'One-Finger Scale' and 'Finger Pattern Study'. The first exercise is a one-octave B flat major scale played on the A string using just the first finger. The finger pattern study is based on this scale but adds a decoration of two consecutive ascending notes to revise the three common finger patterns below the harmonic. (For example, Bb-C-D-C-Bb, C-D-Eb-D-C, etc.) 


\section{Chapter Five: The Higher Positions}

\section{$\underline{\text { Suzuki Cello Volume Six }}$}

The opening piece in Volume Six is 'The Swan' from Saint-Saens' orchestral suite 'The Carnival of the Animals'. The "cellist is challenged to create elegant shapes and impeccable tone in the effortless manner of a graceful and utterly unselfconscious swan." 29 This is an ideal piece for the student to improve their vibrato, as well as continuing to develop good tone and bow control with the long phrases and "graceful, slow moving quarter notes." 30 There are many shifts in the middle of slurs which must be disguised, and the student must play as high as the D above the harmonic (usually thumb position but without the use of the thumb). There is an option to shift up the D string at the end so that the student becomes more familiar with this area of the cello.

The second piece in this book is a movement from a violin concerto that has been transcribed for the cello. It does not appear in the violin books. 'Allegro' from Vivaldi's 'Concerto in D major, Op. 3 No. 9' is a fast piece consisting of semiquavers and many position changes, more so than a violinist as they have a greater reach in each position. This piece has many sequences and revises all of the finger patterns but does not introduce any new material.

After 'Allegro' are two exercises: 'Thumb Scale' and 'Finger Pattern Study'. These two exercises are almost identical to those included at the end of Volume Five, however the exercises in Volume Six have been inserted in the book to develop the correct angle and shape of the hand in thumb position. The thumb scale is a one-octave D major scale ascending and descending on the A string using just the thumb. The finger pattern study expands on this scale by adding an ascending and descending tetrachord from the thumb each time a new note is played. This teaches the four common finger patterns in thumb position.

\footnotetext{
${ }^{29}$ Watkins, Cornelia. [2016] The Swan. [online] CMP Teaching Plan. Available at: https://wmeamusic.org/files/2016/03/CMPtp2009_Studio_TheSwan.pdf. [Accessed 16 Nov. 2019]. p.2. 30 Ibid., p.1.
} 
A tarantella is a "folk dance of southern Italy"31 and the dance was "revived as a concert piece in the 19th and 20th centuries." 32 Squire's 'Tarantella' Op. 23 is no exception; it is a fast dance in 6/8 time, alternating "between major and minor mode and gradually [increasing] in speed." 33 This tarantella is constructed with scales and arpeggios, the scales introducing the use of the thumb as a passing note for the first time in the Suzuki repertoire. There is a great need for bow conservation, as occasionally the student is expected to play more than two bars in one bow. There is a new bowing combination of one accented note followed by five in the corresponding up-bow; this is similar to a passage in 'Allegro Moderato' from Volume Three.

The fourth piece in Volume Six is 'Rondo' from Bréval's Concerto No. 2 in D major. Although 'Rondo' is from Bréval's concerto for cello and orchestra, the version for cello and piano was arranged by Louis Feuillard. It is the first full cello concerto movement in the Suzuki Cello Volumes and it is the first in the repertoire to use thumb position as a proper position rather than just an exercise or passing note. The piece uses the most common position of the thumb on the halfway harmonics, and the thumb is also used closer to the nut as a stopped note. The thumb position in this piece only uses one finger pattern - a tone ascending followed by a semitone - as it is the easiest pattern to learn. There are double stops in thumb position, which have not been used before, and the upper register of the D string becomes more familiar to the student.

The opening movement from Vivaldi's 'Concerto in G minor for Two Cellos', RV531, is the final piece in Volume Six. As there are two cello parts for this concerto, both parts are included in the book. This is similar to the violin books which include Bach's Concerto for Two Violins in D minor, BWV 1043, the "Double Concerto". The student should expect to learn both cello parts, as should the violinists when they learn the second part in Volume Four and the first part in Volume Five. The two solo cello parts are very similar; in many places the material, although played at different times by each player, is identical.

This piece continues the development of the baroque style and consists of many patterns and sequences with primarily scales and arpeggios. There are fast trills towards the beginning of

\footnotetext{
${ }^{31}$ Schwandt, E. (2001). Tarantella. [online] Grove Music Online. Available at: https://www.oxfordmusiconline.com [Accessed 25 Aug. 2019].

${ }^{32}$ Ibid.

${ }^{33}$ Ibid.
} 
the work and quick shifts throughout. The consecutive octave leaps in the last solo section are challenging as they require great agility and consistent accuracy.

This Volume teaches the higher positions around and above the 'halfway harmonic', as well as continuing to develop the student's bowing techniques, bow control, and musical style. Thumb position is introduced and used in the repertoire, and the choice of primarily fast pieces allows the student to work on their finger dexterity both below and around the harmonic and in thumb position. By this point the student's sense of the geography of the cello should be well developed.

\section{$\underline{\text { Suzuki Cello Volume Seven }}$}

To begin Volume Seven, the editors added a recommendation from the International Suzuki Association's Cello Committee to suggest that the entire Suite No. 1 in G major by J. S. Bach be taught before the student completes Volume Eight. Editing (of the likes of bowing, fingering, and articulation) is at the discretion of the teacher. ${ }^{34}$ The student is expected to begin work on the suite by Volume Seven and to complete it before they begin Volume Nine. As there are four manuscripts with inconsistent bowings and articulations, Hee-Young Kim states that bowing and articulation choices are "a source of endless debate for any cellist." 35 The teacher and advanced student will use their own discretion when learning the suite.

The first work in Volume Seven is 'Largo and Allegro' from the Sonata in G minor by Eccles. These two movements are taken from Eccles' four-movement violin sonata, the original version appearing in the Suzuki Violin Volume Eight.

The first movement, 'Largo' is all in tenor clef and continues the solidification of the Baroque style as well as all positions below and around the harmonic. There are a few awkward position changes, and an introduction to 'thumb position pattern three' where the semitone is between the thumb and first finger and between each finger is a whole tone. The student must work on smooth shifting under a slur as well as a beautiful tone and consistent vibrato.

\footnotetext{
${ }^{34}$ Suzuki, Dr, S. (2003) Suzuki Cello School, Volume 7: Cello Part: Revised Edition. . Miami, FL: SummyBirchard, Inc. p.3.

${ }^{35}$ Lim, H. (2019). “Cellist Hee-Young Lim Shares Why She Will Never Stop Studying Bach's Cello Suites”. Strings, [online]. p.291. Available at: https://stringsmagazine.com/ [Accessed 16 Nov. 2019].
} 
'Allegro' is a very quick movement with many fast shifts, more triple stopping and an optional quadruple stopped chord (which was not possible in the original violin version). Due to the fast nature of the movement, the student must have accurate fingers and know the positions and shifts extremely well.

The 'Bourrées' from J.S. Bach's Cello Suite No.3 in C major, BWV 1009 follow the sonata by Eccles. As mentioned before, this is the second piece to be seen in both the cello and violin volumes as it appears in the Suzuki Violin Volume Three. This work is introduced earlier in the violin repertoire as violinists do not need any position shifts to play the piece, however cellists play up to sixth position which makes this piece more challenging.

There is a new bowing pattern introduced in 'Bourrée I', which is three slurred notes followed by a single note. Careful bow control and bow division is imperative here so that the student may keep their bow positioned close to the frog. "The articulation is pointed and clearly etched; the musical lines are direct and forward in feeling. The bouncy, lively, and positive feel of the movement work together to give it an unmistakable dance vibe."36

The second of the two bourrées is in C minor and the first half is all played on the D (and occasionally G) string to achieve a darker tone. This movement is primarily made up of scalic passages and requires intentional note-learning and bowing practice. "Rhythmically, this bourree is very similar to the first (eighth and quarter note juxtaposition, for example), but articulations are smoothed out, and the sections feel like beautifully continuous long phrases." ${ }^{37}$ As was the custom, the student repeats 'Bourrée I' playing each section only once ("A B"); the first time through this bourrée the two sections were both repeated ("AA BB").

David Popper, the composer of the following work, was a renowned, respected cellist of the nineteenth century and an influential cellist-composer. Popper wrote over "75 works, mostly for his own instrument. His most important contribution is certainly the Hohe Schule des Violoncello-Spiels, a set of 40 studies that examine the position of the left hand within a

\footnotetext{
${ }^{36}$ Costanza, C. (2012). Suite No. 3 in C major | The Cello Suites of J.S. Bach. [online] Costanzabach.stanford.edu. Available at: https://costanzabach.stanford.edu/ [Accessed 18 Nov. 2019]. ${ }^{37}$ Ibid.
} 
highly chromatic, Wagner-influenced setting." 38 As the student approaches the professional repertoire, they should be introduced to Popper's Etudes and eventually include them as part of their daily routine. This is an ideal point in the repertoire to introduce them to the student.

'Gavotte' Op. 23 No. 2, by Popper, is a lively dance with a few new cello techniques introduced. It is technically quite a step up from the preceding Eccles Sonata and Bach Bourrées. This piece is in two sections, and although these are not indicated as two gavottes in the score there is a clear change to the mosso section in $\mathrm{D}$ minor before the da capo to the first gavotte in D major occurs. As stated on Oxford Music Online, "occasionally two gavottes occurred consecutively in a suite, the first then repeated da capo." 39

The first gavotte is in rondo form, with the opening 8-bar theme appearing between each new section. A new bowing challenge in this gavotte is the staccato bowing seen in the second section of the piece. The student is playing in thumb position on the A string, a place where more bow is needed to execute a good sound, and they are instructed to play fourteen consecutive notes with an up-bow. Louis Potter describes this as "a succession of miniature martelé strokes, on the string, played in one bow direction." 40 This technique is explained by So Youn Park in the following way: "The firm pressure applied to the bow by the first finger and thumb should immediately be released to produce each tone for the slurred staccato ... In addition, the wrist should be flexible and the arm relaxed."41 The second new bowing technique taught is sautillé (Fr.), or saltato (It.), which is a "bowstroke played rapidly in the middle of the bow, one bowstroke per note, so that the bow bounces very slightly off the string of its own accord." 42 This sautillé stroke, as the notes are slow, gives the student the opportunity to learn the concept and feeling of the bouncing bow before having to put into practice the faster sautillé stroke in Volume Eight.

Another new cello technique introduced is the use of natural harmonics at the end of the fingerboard, as well as a few new natural harmonics in third position (including two seen in 'Scherzo' from Volume Three). The student has not yet played as high in the register as this,

\footnotetext{
${ }^{38}$ Moskovitz, M. (2001) Popper, David. [online] Grove Music Online. Available at: https://www.oxfordmusiconline.com. [Accessed 22 Nov. 2019].

${ }^{39}$ Little, M., and Werley, M. (2001) Gavotte. [online] Grove Music Online. Available at: https://www.oxfordmusiconline.com. [Accessed 23 Nov. 2019].

${ }^{40}$ Potter, L., [1980]. The Art of Cello Playing. Princeton, N.J.: Summy-Birchard Music Inc.. p.121.

${ }^{41}$ Park, S. (2007). Effective Practice Methods for David Popper's Virtuosic Pieces and the Relationship Between Selected Pieces and Etudes. PhD Thesis, Florida State University. p.10.

${ }^{42}$ Boyden, D., and Walls, P. (2001) Sautillé. [online] Grove Music Online. Available at: https://www.oxfordmusiconline.com. [Accessed 23 Nov. 2019].
} 
having only played up to thumb position which is the interval of a seventh below these harmonics. So Youn Park suggests that to "produce a natural harmonic sound, the bow should go close to the bridge and needs more bow speed." 43 This accurate statement poses a problem to the student, as they have a slur of twelve notes with the last three as harmonics. Bow conservation is something the student has been working on, particularly in the cellist William Squire's works in Volumes Five and Six, and they should be confident with their bow work in this passage.

The mosso section, or the second gavotte, is in a very short ternary form with a short 6-bar 'coda' before the da capo occurs. It is a fast work, consisting primarily of slurred quavers, and requires finger agility and smooth string crossings. The thumb position passage reintroduces double stopping which was briefly covered in Rondo from Volume 6. This section has the extra difficulty of a string crossing under a slur as the student plays one note on the A string before double stopping on the A and D string. As the student plays a fingered note on the D string the level of the string is lowered, so they have to anticipate the note by placing their finger in advance.

The final piece in Volume Seven is 'Sicilienne' by the blind Austrian composer von Paradis. This is the only piece in the cello volumes to be attributed to a female composer, although there is some speculation about the work's authenticity. According to Oxford Music Online, "the famous Sicilienne is spurious, probably the work (after a Weber Violin Sonata Op. 10 No. 1) of its purported discoverer, Samuel Dushkin." 44 This slow 'Sicilienne' is in 6/8 time, and it is in E flat major with many unexpected chord progressions and tonalities - $\mathrm{C}$ flat is introduced for the first time, and there are also D flat major and E diminished chords in the piano part. The other new and technically challenging factor is the shift from $\mathrm{E}$ and $\mathrm{F}$ to a high D flat on the A string; the diminished 7th from E to D flat is hard to pitch and as it is so high it has no point of reference.

\footnotetext{
${ }^{43}$ So Youn Park, Effective Practice Methods for David Popper's Virtuosic Pieces and the Realtionship Between Selected Pieces and Etudes. p.12

${ }^{44}$ Angermüller, R., Matsushita, H., and Rabin, R. (2001) Paradis [Paradies], Maria Theresia. [online] Grove Music Online. Available at: https://www.oxfordmusiconline.com. [Accessed 23 Nov. 2019].
} 


\section{Chapter Six: The Professional Repertoire}

\section{$\underline{\text { Suzuki Cello Volume Eight }}$}

To start Volume Eight, the editors added the note of recommendation seen at the start of Volume Seven that the student learns the entire Suite No. 1 in G major by J.S. Bach before the student completes Volume Eight.

The first work in Volume Eight is a sonata attributed to G.B. Sammartini; 'Sonata in G major'. However, as with many of the older pieces in the repertoire, there is some debate over its authenticity. Musicologist Bathia Churgin stated that it falls into the "doubtful and spurious" ${ }^{46}$ category of Sammartini's works, that the style is not Sammartini's, and that when this sonata first appeared, it was attributed to "Martino", an alternative name that Sammartini was known by. Scholars now attribute the sonata to the French cellist-composer Martin Berteau. $^{47}$

There are a lot of passages in thumb position throughout 'Allegro', more than have been seen before, and there are more leaps rather than the previously seen stepwise motion. Double stops, which have not been used much unless an open string (or thumb) is involved, are very prominent in this movement with sixths, fifths, fourths, thirds, tritones, an octave, a tenth, and a diminished seventh. There are also many broken chords throughout the last section of the page which are similar to those seen in 'Rondo' by Goltermann in Volume Five.

The second movement of this sonata, 'Grave', is a typical baroque slow movement with many short phrases of varying lengths, a few challenging octave leaps, and two optional uses of the higher register on the D string to stretch the student.

A fast 'Vivace' finishes the sonata. This is the second piece to be written in 12/8 time and has almost constant quavers throughout. Thumb position is a big part of this piece, and as well as the original thumb position, the student must move their thumb to a stopped note for four full bars. There are a few syncopated passages throughout and some unexpected bowing patterns which are not aligned with the beat.

\footnotetext{
${ }^{45}$ Suzuki, Dr, S. (2003) Suzuki Cello School, Volume 8: Cello Part: Revised Edition. Miami, FL: SummyBirchard, Inc. p.3.

${ }^{46}$ Churgin, B. 1975, "G. B. Sammartini and the Symphony." The Musical Times. 116(1583). p.27.

${ }^{47}$ Wyatt, B. 2005, "Cello Forum: Considering the Source", American String Teacher. 55(3), p.36-38.
} 
Saint-Saens wrote 'Allegro Appassionato', Op. 43 in 1873, orchestrating it in 1876, and it appears on numerous professional recitals and recordings. As it is a work from the Romantic era, there are many nuances such as unwritten ritardandos at the end of phrases or when the pitch deepens, and a quick stringendo before the return to the main theme. This theme occurs three times in the short piece, and, as it has a slightly different transitioning phrase each time it returns it requires active memorisation.

A few of the advanced techniques in 'Allegro Appassionato' include a staccato section with eighteen "miniature martelé strokes, on the string, played in one bow direction."48 This is something the student learned in 'Gavotte' by Popper in Volume Seven, when they had fourteen notes in the up-bow. There are a few challenging broken chords with a bowing pattern the student has not seen yet, and a high triple stop in the penultimate bar. The fast semiquavers at the end are slurred in pairs and have an unavoidable shift each bar, which challenges the student's coordination.

Fauré's 'Elegie', Op. 24 is a very slow and morose piece originally intended as the slow movement to a full cello sonata which Fauré never continued. An élégie, or elegy, is a "setting of a poem, or an instrumental piece, lamenting the loss of someone deceased." Counts, general manager and host of the Utah Symphony Orchestra, said of the piece that "the somber straight lines of the Élégie display [Fauré's] lifelong gift for combining passion with grace." 50 (sic) It is one of the only pieces in the Suzuki volumes to have a really deep emotion and meaning behind it, the other being 'Chanson Triste' in Volume Four, as many of the slow pieces throughout the volumes are slow baroque movements or serene character pieces.

The main theme of the piece is played four times, and each repetition has different fingering, positions, and strings, as well as contrasting dynamics and a change of character or emotion.

The final version of this theme is pitched a fifth above the halfway harmonic and is the highest the student has played (with the exception of natural harmonics in Popper's 'Gavotte from Volume Seven which are much easier to play in tune).

\footnotetext{
$\overline{48}$ Potter, L., [1980]. The Art of Cello Playing. P.121.

49 Boyd, M. (2001) Elegy (Fr. Élégie; Ger. Elegie). [online] Grove Music Online. Available at: https://www.oxfordmusiconline.com. [Accessed 25 Nov. 2019].

50 Counts, J. (n.d.). Faure - Elegy. [online] Utah Symphony. Available at: https://utahsymphony.org/ [Accessed 11 Dec. 2019]
} 
Having used syncopation only occasionally, the student must now alternate between syncopated quadruplets, regular duplets, and regular triplets for two phrases. They must also play a bass line while the piano takes the tune, and as they have not had much experience in this - the other occasion being the more straightforward bass lines in Vivaldi's 'Concerto in G minor for Two Cellos' - this section may prove more difficult to memorise. As the student has had a great deal of experience playing fast scalic passages, the quick shifting and long, flowing scales should cause few issues.

The final piece in Volume Eight, and the final non-concerto piece in the cello repertoire, is 'Scherzo Op. 12' by van Goens. 'Scherzo' translates to 'joke' and is defined by the Oxford Dictionary to be a "vigorous, light, or playful composition." 51 This lively showpiece consists mainly of spiccato bowing, and as is typical of a scherzo, there is a contrasting trio section in the middle of the piece; a singing cantando section which has character and dynamic contrasts and includes high natural harmonics similar to those in 'Gavotte' by Popper.

Spiccato can be a challenging technique for students to learn, and in the Suzuki method this technique also poses the challenge of unfamiliarity as the only piece similar to van Goens' Scherzo is Webster's 'Scherzo' in Volume Three. When the student has achieved a good spiccato bow stroke, the next bowing challenge is the off-beat string crossing seen throughout the spiccato sections. As spiccato notes occur in pairs due to the rebounding nature of the stroke, changing in the middle of the pattern feels very unnatural.

This piece introduces some new left-hand techniques with broken minor thirds descending chromatically over an octave using the thumb and second finger. There is also a spiccato scale of a chromatic octave ascending with one finger, and two octaves descending. The speed of this glissando must be carefully controlled so the student arrives on the correct note at the correct time.

\footnotetext{
${ }^{51}$ Russell, T, and Macdonald, H. (2001) Scherzo (It.: 'joke'). [online] Grove Music Online. Available at: https://www.oxfordmusiconline.com. [Accessed 11 Dec. 2019].
} 


\section{Chapter Seven: The Concertos}

\section{$\underline{\text { Suzuki Cello Volume Nine }}$}

When editing the professional repertoire as part of an educational resource, the editors must adhere to the markings in the score as much as possible to avoid disagreements and in order to please as many musicians as possible. Haydn is a composer of music with which one is able to do this. We have a very clear idea of Haydn's intentions for bowing and articulation due to the availability and clarity of his manuscript parts; however sparse the bowing may be, it is reasonably consistent. The Bach cello suites (and many other works from around that time) are a different matter, as the four original manuscript copies of the scores are not consistent amongst each other or within themselves. There are many unwritten performance rules with baroque music where the performer must decide on their interpretation at their own discretion. Teachers and advanced students will have very different opinions on articulation and bowing, and the unclear manuscript(s) makes editing the repertoire as part of an educational resource a nearly impossible task.

Volumes Nine and Ten both tell the reader that "under the guidance of Dr. Suzuki since 1978, the editing of the Suzuki Cello School is a continuing cooperative effort of the Cello Committees from Talent Education Japan, the European Suzuki Association and the Suzuki Association of the Americas." 52 The current International Cello Committee consists of four members: committee chair Akira Nakajima from the Talent Education Research Institute; Pan-Pacific representative Sally-Anne Alloway, Ruben Rivera from the European Suzuki Association; Barbara Wampner from the Suzuki Association of the Americas. Two of these cellists, Akira Nakajima and Barbara Wampner, were on the committee at the time of editing the published Suzuki cello part, along with Takao Mizushima, Haukur Hannesson, and advisor Tanya Carey. ${ }^{53}$

This committee decided every bowing and fingering that is printed in this volume, as well as the alternate fingering provided. The bowing does not have scope for any difference due to the expectation that students will play together and therefore should be doing the same

\footnotetext{
${ }^{52}$ Suzuki, Dr, S. (1996) Suzuki Cello School, Volume 9: Cello Part. Miami, FL: Summy-Birchard, Inc. p.2. Also in: Suzuki, Dr, S. (1996) Suzuki Cello School, Volume 10: Cello Part. Miami, FL: Summy-Birchard, Inc. p.2.

${ }^{53}$ International Suzuki Association. (1996). ISA Committees. International Suzuki Journal 7(1), p.2.
} 
bowing. The original manuscript version of the cello part is included in the piano part and therefore excludes any slurs edited into the Suzuki edition. The edited dynamics are used for ease of performance. ${ }^{54}$ The manuscript seems to be reasonably consistent, and although there are few slurs or bowing directions, the bowing that is present is clear. Sally-Anne Alloway, with the exception of one slur, teaches the concerto with the printed bowings but is open to different fingerings which may suit individual students better. ${ }^{55}$ This allows students to play together as a group and to look unified as an ensemble, and for the teachers at workshops and camps to have consistency when teaching this piece in a masterclass or group lesson.

Haydn's manuscript does not give the performer as much artistic licence; much less freedom than other standard cello concertos such as Dvorak, Schumann, and Elgar. The style of this work, as well as the clarity of the manuscript, makes this concerto an ideal choice for the Suzuki Volumes. The Suzuki method is aimed at starting very young children, and due to the early starting age and immersion in music they often progress quickly through the books. They then reach Volume Nine and Haydn's concerto at a young age, in some cases younger than ten years old. According to Ms Alloway, New Zealand's only cello teacher trainer and the Pan-Pacific representative on Suzuki's International Cello Committee, this piece is not musically complicated and therefore is achievable for a young cellist. They may not yet have the musical maturity required to play Romantic concertos, however a Baroque or early Classical concerto requires very technical playing with a high level of control.

Having worked their way through the previous eight Volumes, the student should be technically set up and prepared to play this concerto. Their thumb position will have been worked on since Volume Four, and their bow control has been developing from the first stopped bow which is what Ms Alloway calls "the essence of the Suzuki sound." ${ }^{56}$ At this level there are greater expectations for consistency of intonation, and they will have the ability and coordination to play very fast. Ms Alloway suggested that if the student is not technically ready for the concerto they could do the following: review Volume Six for fast and coordinated playing; introduce Popper Etudes, Piatti Caprices, or other similar studies; learn a selection of supplementary pieces listed at the beginning of Volume 9 (Scherzo by van Goens; Hungarian Rhapsody by Popper; Kol Nidrei by Bruch; Played before Volume 9: Suite

\footnotetext{
${ }^{54}$ Suzuki, Dr, S. (1996) Suzuki Cello School: Piano Accompaniments: Volume 9. Miami, FL: Summy-Birchard, Inc. p.2.

55 Alloway, S. (2020). Skype conversation with Rebecca Harvey, 4 Feb. 2020

${ }^{56}$ Ibid.
} 
in $\mathrm{G}$ for Solo Cello by $\mathrm{Bach}^{57}$ ); or sit a Grade Eight exam. ${ }^{58}$ The Suzuki student is not compromised by this revision schedule; they rely on the teacher to ensure they are ready and capable of the next piece before moving on.

The repertoire in Volume Nine is solely the three movements of Haydn's Concerto in C major, however the volume contains two pages of tonalisation, etudes, and exercises. With the exception of three preparatory exercises, these are all previously learned pieces in different positions. In order of appearance, they are: 'Chorus' (an excerpt); 'Etude'; 'Perpetual Motion' with duplet and triplet variations, played 'at tempo of concerto'; and 'Rigadoon'. These all start with the thumb resting on the halfway harmonic, and 'Chorus' indicates that the student also starts from three different positions using the same notes in order to practice different finger patterns. To continue the technical exercises, the volume reintroduces the one-finger scale first seen at the end of Volume Five. This again reviews all common finger spacings.

Haydn's 'Cello Concerto in C major, Hob. VIIb. 1' was written in around 1761-65 for a very specific audience: his employer (either Prince Paul Esterházy or the Prince's brother Nikolaus) and the prince's Hungarian court. Haydn was employed to write music that reflected "well upon the Prince, showing him to be a man of impeccable taste and abundant riches." 59 The opening theme was entered into Haydn's music catalogue of 1765, to prove to Prince Nikolaus Esterházy that he was working diligently, and into his personal catalogue of 1805, which was "disarmingly titled, 'List of all the compositions which I can at present remember having composed from my eighteenth until my seventy-third year'." this work was presumed lost until 1961, when musicologist Oldřich Pulkert discovered a copy of the score at the Prague National Museum, ${ }^{61}$ two centuries later. H. C. Robbins Landon has described this discovery as "the single greatest musicological discovery since the Second World War."62

\footnotetext{
${ }^{57}$ Suzuki, Dr, S. (1996) Suzuki Cello School, Volume 9: Cello Part. P.2.

${ }^{58}$ Alloway, S. (2020). Skype conversation with Rebecca Harvey, 4 Feb. 2020

${ }^{59}$ Furse, E. (2009). Perspectives on the reception of Haydn's Cello Concerto in $C$, with particular reference to musocological writings in English on Haydn's concertos and the classical concerto. Mmus. University of Birmingham. P.4

${ }^{60}$ Steinberg, M. (2018, posth.). Haydn: Cello Concerto No. 1. [online] San Francisco Symphony. Available at: https://www.sfsymphony.org/ [Accessed 2 Dec. 2019].

${ }^{61}$ Haydn, J, trans. Clément, R. (2007). Konzert in C für Violoncello und Orchester. Kassel, Germany: Barenreiter-Verlag. P. 5-6.

${ }^{62}$ Landon, H. (1998). The Pre-Classical Concerto and the Concerto Parallel to Mozart. In: R. Layton, ed., A Companion to the Concerto. Oxford: Oxford University Press, p.63.
} 
The concerto was written very early in the Classical period, and the Baroque style is still very present in this composition. It continues the Baroque influence of the past eight Volumes, as the student must have a very clean sound, precise articulation, and good bow control.

Each of the three movements in Haydn's first cello concerto begins with a long orchestral introduction, or piano reduction for the Suzuki student. The three movements are in sonata form, with three sections to each movement: the double exposition, the development, and the recapitulation. There are substantial orchestral sections in each of the movements, and the student must know when to prepare to play. The only other piece to have any orchestral (or piano) interlude is Goltermann's 'Rondo' in Volume Five.

There are a lot of different technical challenges involved when preparing for this concerto. The first movement starts with a quadruple stop, and there are triple stops and double stops throughout the whole movement. This is challenging for the bow control and angle and also the sound quality. The second and third movements contain many double stops, but no triple or quadruple stops. The most challenging double stopping is seen in thumb position, with double stops in four of the nine thumb positions in this piece. This technique was covered extensively in 'Scherzo' by van Goens, where the student played thirds with the thumb and second finger only. In Haydn's concerto, the thirds are between the thumb and second finger, but also between the first and third fingers, and with the thumb as a drone while the tune is played on the lower string. This intonation proves much more difficult to play in tune.

This concerto, and Boccherini's subsequent concerto in the next volume, requires very accurate and tidy fingerwork. There are many fast passages in both the first and third movements, and occasional passages in the higher register across all three movements. The Suzuki student has had some experience in the higher registers, but this is the highest that they have played, and the highest that the thumb has been used. 
The Suzuki student has never played a cadenza, or any other form of un-metred music before, so the concept of playing freely is new to them. The first and second movements of Haydn's concerto both include a short cadenza which was written anonymously in the eighteenth century and is included in the urtext edition of the work. This cadenza gives the teacher the opportunity to discuss the use of scales and arpeggios in cadenzas and the way in which material from the concerto is used and partially altered. The use of scales and arpeggios is particularly clear in the cadenza to the second movement of this concerto, as the whole cadenza revolves around decorated scales and one arpeggio.

Haydn's opening 'Moderato' movement is lively and bright, and it starts with a dotted rhythm and some fast semiquaver slurs at the tip. There are many short and fast notes at the end of the bow, which requires nuanced control and understanding of the weight distribution in the bow. Partway through the development section there are very quick broken chords with an optional saltando bowing that requires a lot of coordination and anticipation from the bow.

The second movement, 'Adagio', has the hardest and highest thumb position the student has played in the Suzuki volumes thus far. The thumb is placed a minor third minor higher than the halfway harmonic, and it is more difficult to hold down the thumb in this position due to increased tension. This is contributed to by the concave dip in the fingerboard, which increases the distance between the strings and fingerboard and therefore the force required to lower the string. The thumb position here also includes a drone where the thumb holds the top note and the moving notes are on the lower string. The thumb must be firm and unwavering to keep the pitch constant, and the lower notes must match the intonation of the held drone.

'Allegro molto', the third and final movement, is a fast and excited piece containing many quick and flourishing scalic passages and a large semiquaver section full of all the different finger patterns which has to be well internalised and memorised. There is a bowing pattern of one note followed by seven slurred notes, which is similar in principle to the pattern first seen at the end of Volume Three (in 'Allegro Moderato'), but much harder as it is faster and adds extra notes to the slur. 


\section{$\underline{\text { Suzuki Cello Volume Ten }}$}

The tenth and final volume in the Suzuki Cello Method contains Grützmacher's arrangement of Boccherini's 'Concerto in Bb major'. However, before the student begins working on the concerto they have seven pages of exercises to work through, as well as recommended supplementary repertoire listed at the beginning of the book: Adagio by Bach/Siloti, Toccata by Frescobaldi/Cassado, and The Bee by F. Schubert. ${ }^{63}$ The technical exercises are classified as 'Tonalisation' or 'Practice Points'. The tonalisation exercises consist of: 'Long Long Ago' (Volume One) in Bb major; 'French Folk Song' (Volume One) in thumb position, in Bb major and in F major; and 'Allegretto' (Volume One) in C major, starting with the thumb a minor third above the halfway harmonic and also a major third below the halfway harmonic. The 'Practice Points' are specific to the concerto and consist of bow strokes, double stops in all positions including thumb position, octave shifting, and diminished arpeggios.

Luigi Boccherini was one of the greatest cellists of the eighteenth century. At the "age of nine, Boccherini was studying with the Maestro di Cappella at the San Martino Cathedral, and four years later, he had surpassed even his teacher in technique." ${ }^{\prime 64}$ Very soon after this, Boccherini travelled to Rome to continue his music training and is said to have studied with virtuoso cellist Giovanni Battista Costanzi. ${ }^{65}$ By the age of thirteen, he had made his debut with a cello concerto (it is not known which concerto he played) and judging by the fees he requested at the many festival appearances he must have already been regarded as one of the city's finest musicians. ${ }^{66}$

"Virtuoso performers at this time often had to write music for themselves in order to exhibit fully their musical and technical abilities", ${ }^{67}$ and according to Yves Gerard, the some twenty sonatas composed before Boccherini's twenty-fifth year, and the six (authentic) concerti composed prior to 1771, all testify to the cellistic skill which their author must have possessed. ${ }^{6}$ "The sheer variety of technical demands and the wealth of musical interest in his

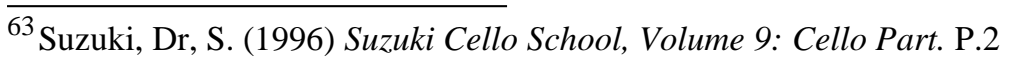

${ }^{64}$ Campbell, M. (1988). The Great Cellists. London: Victor Gollancz Ltd. P.48

${ }^{65}$ Speck, C., and Sadie, S. (2001) Boccherini, (Ridolfo) Luigi. Grove Music Online. Available at: https://www.oxfordmusiconline.com. [Accessed 28 Nov. 2019]. 66 Ibid.

${ }^{67}$ Raychev, E. (2003). The Virtuoso Cellist-Composers from Luigi Boccherini to David Popper: A Review of their Lives and Works. Ph.D. The Florida State University. P.8.

${ }^{68}$ Gerard, Y. (1969), Thematic, Bibliographical and Critical Catalogue of the Works of Luigi

Boccherini. London: Oxford University Press. P.3.
} 
cello works make them not only a textbook of eighteenth-century cellistic possibilities but an essential component of every cellist's repertoire." 69

Boccherini's 'Cello Concerto No. 9 in Bb major, G. 482', was written around the year 1770, when Boccherini was less than thirty years old. It is the most well-known of Boccherini's concertos, and it is "familiar in the regrettable arrangement published by Friedrich Grützmacher in 1895." ${ }^{, 70}$ Boccherini was known to borrow his own thematic material, or on occasions to substitute a whole movement in the work he was composing, and while editing Boccherini's concerto Grützmacher took the liberty of partially recomposing the work. Both the solo and orchestral parts were altered through the "conflation of a sonata" (G.565) and the original concerto (G.482), with “Grützmacher's own glosses to the harmony, orchestration and solo figuration."71 The "slow movement was substituted from another concerto in much the same way that Boccherini recycled his own material; the original slow movement is replaced" with the edited and extended "second movement of the Concerto No. 7 in G Major, G 480. In this respect, it seems entirely possible that Boccherini would have approved of Grützmacher's changes."72

Grützmacher's editing and recomposing was not discovered until Richard Sturzenegger published his "original" version in 1949, and it was thereafter considered a vandalized version. ${ }^{73}$ However, even the "original" published version was edited: "The first edition of the B-flat concerto which presented a reasonable approximation of the original text ... even though here, too, the editor, Richard Sturzenegger admits to having revised the work in certain aspects." 74 This editing was primarily to compose independent viola parts for the orchestral sections of the work, however in his, preface, Sturzenegger omits to mention that he also "recomposed a fairly substantial portion of the accompaniment, adding parts and occasionally altering harmonies, without indicating in any manner the nature of the changes or where they occur. Thus, even the edition which claims to set right the "wanton" interventions of Grützmacher must be regarded with due suspicion." 75

\footnotetext{
${ }^{69}$ Collorafi, J. (1988) Luigi Boccherini: Six Cello Concerti; a Critical Edition. Ph.D. Indiana University. P.1-2.

${ }^{70}$ Speck, C., and Sadie, S. (2001) Boccherini, (Ridolfo) Luigi.

${ }^{71}$ Ibid.

${ }^{72}$ Raychev, E. (2003). The Virtuoso Cellist-Composers from Luigi Boccherini to David Popper: A Review of their Lives and Works. P.12.

${ }^{73}$ Scott, M. (1984). "Boccheriniees B Flat Cello Concerto: A Reappraisal of the Sources." Early Music 12(3), p. 355-357.

${ }_{75}^{74}$ Collorafi, J. (1988) Luigi Boccherini: Six Cello Concerti; a Critical Edition. P.7.

75 Ibid., p.8.
} 
Boccherini's concerto is very different to Haydn's concerto. Although the two concertos were written within a decade of each other, Haydn's is a very clean and precise German concerto and Boccherini's concerto is a more romantic Italian concerto. Boccherini's concerto still requires the same clean sound and precise articulation as seen in Haydn's concerto; however the sound must also be very florid. The student must add the next stylistic and musical layer to their playing.

Technically the concerto in B-flat Major is very challenging. The range of the solo part is extended hugely, up to Bb", in the finale, and, according to James Collorafi, more "demands are made upon the endurance in thumb position playing than in any of [Boccherini's] previous concerti." 76 There are also some unusual technical problems that arise which do not occur in the other concertos; "rapid chromatic scales ... arpeggios spanning one octave which must be played on one string with a hyperextended third finger ... and extended arpeggios on the A-string which lie well beyond the fingerboard of the classical cello." 77

All three movements of Boccherini's concerto have cadenzas written by Grützmacher, with a second option by Pablo Casals for the third movement. This is another opportunity for the teacher to discuss the purpose a cadenza serves and why they were used, and will also cover topics such as keys, chordal progressions, and the compositional style.

The first movement of this concerto is titled 'Allegro Molto' and is in sonata form with a brief orchestral introduction. There are a lot of fast scales and arpeggiated passages and the finger patterns and extensions must be very well internalised for the student to execute these with success. The cello part travels very high, to the Bb"' mentioned earlier, and the student reads their first double sharp in this movement.

Bow control is important through the development section as the student plays a sequence of broken chords. The student must also demonstrate a very good sense of rhythm as the note values change between triplets and quadruplets. The movement ends with a cadenza entirely

\footnotetext{
${ }^{76}$ Collorafi, J. (1988) Luigi Boccherini: Six Cello Concerti; a Critical Edition. P. 10. ${ }^{77}$ Ibid., p.10.
} 
by Grützmacher, in a "thoroughly $19^{\text {th }}$-century virtuoso style"78 with many double stops all over the cello and a lot of fast, flashy passages.

The second movement, 'Adagio non troppo', is an extremely slow movement starting with a held note in the solo cello part. This movement is not technically challenging, much less so than the second movement of Haydn's concerto, however the difficulty in this work is the musical line and song. There is a short cadenza written by Grützmacher which is marked non presto, indicating that the player must take time and play very freely.

The last movement of the concerto, 'Rondo-Allegro', is technically very difficult. There are a lot of thumb stopped notes and double stops using the thumb, and a lot of enharmonic writing (including double flats for the first time) which, although the Suzuki student learns a lot of their music by ear, makes intonation quite challenging. There is an extremely fast sequence towards the end of the movement which requires impeccable accuracy in the left hand and coordination and control with the bow. The solo part finishes with twelve bars of double and triple string crossings (there is a similar passage in the development in a different key) which highlight just how difficult this technique is; the left hand must anticipate and the bow must travel very quickly to achieve a clean and accurate sound.

The first cadenza included for this movement is again written by Grützmacher and is a very virtuosic and 'showy' ending to a very difficult movement. Grützmacher includes many of the themes from the movement in the cadenza such as the scale and arpeggio sequencing and the double string crossings at the end of the movement, as well as the challenging double stops in thumb position from the second subject.

Pablo Casals also wrote a cadenza for this movement, and the Suzuki Cello Committee decided to include this as a second option. It is left up to the teacher to decide whether the student learns both of the cadenzas. Like Grützmacher, Casals' cadenza takes the themes from the third movement and scatters them through the cadenza, however Casals decorates and alters these themes more than Grützmacher which gives the cadenza a much more improvisatory atmosphere. Casals writes many double stops in his cadenza and a lot of very technically challenging passages.

\footnotetext{
${ }^{78}$ Allsen, M. (2019). Peoria Symphony Orchestra Program Notes: March 9, 2019. [online] Available at: https://peoriasymphony.org/ [Accessed 5 Dec. 2019]
} 


\section{$\underline{\text { Beyond Volume Ten }}$}

Having finished the ten Suzuki cello volumes, the student is ready to move on to other professional repertoire such as major concertos, standard sonatas, and showpieces. Although Ms Alloway recognises that it is unusual for students to continue with the Suzuki method once they have finished the two concertos as they either naturally progress on to another teacher or finish high school and move on, she recommends a list of pieces which the student is ready to learn. These include concertos, sonatas, and showpieces, as well as the forty Popper Etudes, twelve Piatti Caprices, and other technical works which allow the student to focus on their technique. ${ }^{79}$

The concertos Ms Alloway suggests include, but are not limited to, the following ordered list:

- Saint-Saëns Cello Concerto No.1 in A minor, Op.33

- Lalo Cello Concerto in D minor

- Elgar Cello Concerto in E minor, Op.85

- Tchaikovsky Variations on a Rococo theme, Op.33

- Shostakovich Cello Concerto No.1 in E-flat major, Op.107

Ms Alloway also recommends learning the following standard sonatas, however notes that this is more challenging unless the student has regular rehearsal time with a pianist. These include, but are not limited to:

- Brahms Sonata in E minor, Op.38

- Shostakovich Sonata in D minor, Op.40

- Beethoven Sonatas 1-5

- Rachmaninoff Sonata in G minor, Op.19

$\overline{79}$ Alloway, S. (2020). Skype conversation with Rebecca Harvey, 4 Feb. 2020 


\section{Chapter Eight: Common Criticisms}

There are a few misconceptions concerning the Suzuki Method, the primary criticisms being that students have "compromised sight reading skills" and "a tendency towards rote learning and 'robotic' group performance at the expense of individual musicianship." 80

The Suzuki Method does not include note reading or music theory, partially due to the fact that Suzuki created the method in a culture where schools taught note reading and music literacy as part of the curriculum. In Lucien Ellington's book 'Asia in Focus: Japan', one finds that despite "periods of time when Japanese music was given a short shrift ... Japanese school curriculum today provides students with an organised music education where they learn both Western and Asian music. ... the Japanese have considered music an important part of the school curriculum and not a frill that is subject to cuts during economic hard times." $" 81$

The Japanese curriculum states three ideals in which they teach. These are:

\footnotetext{
To cultivate an interest in and respect for sound and music, and to foster an attitude of brightening and enriching one's life through music, by experiencing the joy of musical activities.

To perceive the richness and joy of various types of musical expression, acquire basic skills for music-making and foster the ability to make music in a creative and original manner.

To savor the value and beauty of various types of music and foster a wide-ranging and independent ability for appraising. ${ }^{82}$
}

Students are also expected to be able to understand the meaning of the sharp and flat key signatures and should be familiar with sightreading and sight singing scores with simple key signatures. ${ }^{83}$

\footnotetext{
${ }^{80} \mathrm{Ng}$, S. (n.d.). The Suzuki Method - Criticism and Response. [Blog] Dr Shaun Ng: Teacher and Performer of Violins, Viols and Lutes. Available at: http://www.shaunng.com.au/2010/02/suzuki-method-criticism-andresponse.html [Accessed 7 Dec. 2019].

${ }^{81}$ Ellington, L. (2009). Asia in Focus: Japan. Santa Barbara, CA: ABC-CLIO, p.283.

${ }^{82}$ Ministry of Education, Culture, Sports, Science and Technology (MEXT). (2015) Junior High School Course of Study Guide English Translation Version. [online] www.mext.go.jp. Available at: https://www.mext.go.jp/component/a_menu/education/micro_detail/_icsFiles/afieldfile/2011/04/11/1298356_6.p df [Accessed 12 Feb. 2020]

${ }^{83}$ Ibid.
} 
The mother-tongue approach of the Suzuki Method is also a factor in the delayed sightreading and musical literacy. Children learn to make sounds and to speak much earlier than they learn to read, and Suzuki based his philosophy around this concept. The Suzuki student will start to read when they can play with good tone and are self-correcting their intonation. The starting point is at the teacher's discretion, however if the student begins formal training in sightreading too late they will be much quicker at copying and repeating, as the Suzuki method is such an aurally based method, and less motivated to learn to sightread.

Repetition is a priority for the Suzuki student, and playing with others in Suzuki group lessons and workshops happens regularly. However, this tendency towards rote learning and 'robotic' group performances is one of the criticisms directed at the Suzuki method. Sometimes young students look like they are not concentrating, but Ms Alloway states that every repetition must be mindful. Non-Suzuki teachers also encourage repetition to solidify techniques and learn the notes in the student's current piece; this is a tried and tested way of learning information (musical or otherwise). Suzuki students are also encouraged to think about the musicality of the pieces they are working on, thinking of dynamic contrasts as early as French Folk Song at the start of Volume One or working out the very personal subtleties in rubato and vibrato in the slow movement to Boccherini's concerto in Volume Ten. Playing together in a group encourages the student to listen to how others play the piece and to blend their sound; something that is paramount when playing in an orchestra or chamber group. 


\section{$\underline{\text { Conclusion }}$}

The Suzuki Method has spread from Shinichi Suzuki's music school in 1946 to at least 38 countries worldwide, and through thousands of young musicians over the last 75 years. Students have gone on to play professionally in world-class orchestras and as world class soloists, and for those students that do not continue to play their instrument, they have an appreciation for music which can last a lifetime. This dissertation details to the reader the history of the founder, Shinichi Suzuki, and his teaching method, and explains the philosophy behind Suzuki's work. It shows cello pedagogues with and without experience of the Suzuki community the technical and musical reasons behind the musical works chosen for the cello volumes, with the hope of broadening the reader's knowledge of the overarching method and philosophy and giving a potentially new perspective on the use of the repertoire. It also gives the reader a deeper understanding of why there are two concertos included as part of the method books and the purpose these concerti play. 


\section{Bibliography}

Alloway, S. (2020). Skype conversation with Rebecca Harvey, 4 Feb. 2020.

Allsen, M. (2019). Peoria Symphony Orchestra Program Notes: March 9, 2019. [online] Available at: https://peoriasymphony.org/ [Accessed 5 Dec. 2019].

Angermüller, R., Matsushita, H., and Rabin, R. (2001). Paradis [Paradies], Maria Theresia. [online] Grove Music Online. Available at: https://www.oxfordmusiconline.com. [Accessed 23 Nov. 2019].

Barrett, C. (1995). The Magic of Matsumoto: The Suzuki Method of Education. California: ETC Publications. p.46.

Bauman, S. (1994). In Search of the Japanese Spirit in Talent Education. New Jersey: Summy-Birchard. p.6.

Beaupré, L. (2010). Language: Your Baby's First Steps Toward Learning to Speak. [online] Child-encyclopedia.com. Available at: http://www.childencyclopedia.com/sites/default/files/docs/coups-oeil/language-info.pdf [Accessed 10 Feb. 2020].

Bjork, M. (2008). Expanding Horizons: The Suzuki-Trained Violinist Grows Up. Van Nuys, CA: Alfred Publishing Co. Inc. p.31.

Boyd, M. (2001) Elegy (Fr. élégie; Ger. Elegie). [online] Grove Music Online. Available at: https://www.oxfordmusiconline.com. [Accessed 25 Nov. 2019].

Boyden, D., and Walls, P. (2001). Sautillé. [online] Grove Music Online. Available at: https://www.oxfordmusiconline.com. [Accessed 23 Nov. 2019].

Campbell, M. (1988). The Great Cellists. London: Victor Gollancz Ltd. p.48 
Carpenter, S. (1988). Shinichi Suzuki and His "Mother-Tongue Approach” to Music Education in the United States. Unpublished Master of Fine Arts Thesis. University of Florida: Gainesville, FL. p.6.

Churgin, B. (1975). "G. B. Sammartini and the Symphony." The Musical Times. 116 (1583). p.27.

Collorafi, J. (1988). Luigi Boccherini: Six Cello Concerti; a Critical Edition. Ph.D. Indiana University. p.1-2, 7-8, 10.

Costanza, C. (2012). Suite No. 3 in C major | The Cello Suites of J.S. Bach. [online] Costanzabach.stanford.edu. Available at: https://costanzabach.stanford.edu/ [Accessed 18 Nov. 2019].

Counts, J. (n.d.). Faure - Elegy. [online] Utah Symphony. Available at: https://utahsymphony.org/ [Accessed 11 Dec. 2019].

Edition Silvertrust (n.d.). William Henry Squire: Danse Rustique for Cello and Piano, Op.20 No.5. [online] Editionsilvertrust.com. Available at: http://www.editionsilvertrust.com/squire-danse-rustique.htm [Accessed 1 Oct. 2019].

Ellington, L. (2009). Asia in Focus: Japan. Santa Barbara, CA: ABC-CLIO, p.283.

Eubanks, K. (2015). Essays in the Theory and Practice of the Suzuki Method. D.M.A. City University of New York. p.114

Furse, E. (2009). Perspectives on the reception of Haydn's Cello Concerto in C, with particular reference to musicological writings in English on Haydn's concertos and the classical concerto. MMus. University of Birmingham. p.4

Gerard, Y. (1969), Thematic, Bibliographical and Critical Catalogue of the Works of Luigi Boccherini. London: Oxford University Press. p.3. 
Haydn, J, trans. Clément, R. (2007). Konzert in C für Violoncello und Orchester. Kassel, Germany: Barenreiter-Verlag. p. 5-6.

Hermann, E. (1981). Shinichi Suzuki: The Man and His Philosophy. Miami, FL: Summy-Birchard Music. p.5.

International Suzuki Association. (1996). ISA Committees. International Suzuki Journal 7 (1). p.2.

Landers, R. (1984). The Talent Education School of Shinichi Suzuki-An Analysis: The Application of Its Philosophy and Methods to All Areas of Instruction. New York: Exposition Press. p.7.

Landon, H. (1998). The Pre-Classical Concerto and the Concerto Parallel to Mozart. In: R. Layton, ed., A Companion to the Concerto. Oxford: Oxford University Press. p.63.

Lavie, K. (2005). "On Gastronomy and Tonalization." New Zealand Suzuki Journal 16 (4). p. 5-6.

Lim, H. (2019). “Cellist Hee-Young Lim Shares Why She Will Never Stop Studying Bach's Cello Suites". Strings, [online]. p.291. Available at: https://stringsmagazine.com/ [Accessed 16 Nov. 2019].

Little, M., and Werley, M. (2001) Gavotte. [online] Grove Music Online. Available at: https://www.oxfordmusiconline.com. [Accessed 23 Nov. 2019].

Luxenberger, C. (1997). The developing role of the recorder in the conservatories and music schools of the Netherlands from post-World War II to 1980. Ph.D. University of Houston. p. 122. 
Ministry of Education, Culture, Sports, Science and Technology (MEXT). (2015) Junior High School Course of Study Guide English Translation Version. [online] www.mext.go.jp. Available at:

https://www.mext.go.jp/component/a_menu/education/micro_detail/_icsFiles/afieldfile/2011/ 04/11/1298356_6.pdf [Accessed 12 Feb. 2020].

Moskovitz, M. (2001) Popper, David. [online] Grove Music Online. Available at: https://www.oxfordmusiconline.com. [Accessed 22 Nov. 2019].

Ng, S. (n.d.). The Suzuki Method - Criticism and Response. [Blog] Dr Shaun Ng: Teacher and Performer of Violins, Viols and Lutes. Available at: http://www.shaunng.com.au/2010/02/suzuki-method-criticism-and-response.html [Accessed 7 Dec. 2019].

Park, S. (2007). Effective Practice Methods for David Popper's Virtuosic Pieces and the Relationship Between Selected Pieces and Etudes. PhD Thesis. Florida State University. p.10, 12 .

Potter, L. [1980]. The Art of Cello Playing. Princeton, N.J.: Summy-Birchard Music Inc. p.121.

Rainbow, B. (2013). Music Education, Yesterday, Today and Tomorrow. In Dickinson P. (Ed.), Music Education in Crisis: The Bernarr Rainbow Lectures and Other Assessments. Woodbridge, Suffolk, UK; Rochester, NY, USA: Boydell \& Brewer. p.129-138.

Raychev, E. (2003). The Virtuoso Cellist-Composers from Luigi Boccherini to David Popper: A Review of their Lives and Works. Ph.D. The Florida State University. p.8, 12.

Russell, T, and Hugh Macdonald, H. (2001). Scherzo (It.: 'joke'). [online] Grove Music Online. Available at: https://www.oxfordmusiconline.com. [Accessed 11 Dec. 2019].

Samson, J. (2001). Romanticism. [online] Grove Music Online. Available at: https://www.oxfordmusiconline.com [Accessed 12 Aug. 2019]. 
Schwandt, E. (2001). Tarantella. [online] Grove Music Online. Available at: https://www.oxfordmusiconline.com [Accessed 25 Aug. 2019].

Scott, M. (1984). "Boccherini's B Flat Cello Concerto: A Reappraisal of the Sources." Early Music, 12 (3). p.355-357.

Speck, C., and Sadie, S. (2001) Boccherini, (Ridolfo) Luigi. Grove Music Online. Available at: https://www.oxfordmusiconline.com. [Accessed 28 Nov. 2019].

Steinberg, M. (2018, posth.). Haydn: Cello Concerto No. 1. [online] San Francisco Symphony. Available at: https://www.sfsymphony.org/ [Accessed 2 Dec. 2019].

Suzuki Talent Education Program. (n.d.). Suzuki Program Information. [online] Available at: https://stepbrandon.weebly.com/about.html [Accessed 26 Jun. 2019].

Suzuki, S. (1969). Nurtured by Love. Miami, FL: Summy-Birchard, Inc. p.68-69.

Suzuki, S. (1982). Suzuki Cello School, Volume 1: Cello Part: Revised Edition. Miami, FL: Summy-Birchard, Inc. p.14-15.

Suzuki, S. (1992). Suzuki Cello School, Volume 2: Cello Part: Revised Edition. Miami, FL: Summy-Birchard, Inc. p.8.

Suzuki, S. (1996). Suzuki Cello School, Volume 10: Cello Part. Miami, FL: Summy-Birchard, Inc. p.2.

Suzuki, S. (1996). Suzuki Cello School, Volume 9: Cello Part. Miami, FL: Summy-Birchard, Inc. p.2.

Suzuki, S. (1996). Suzuki Cello School: Piano Accompaniments: Volume 9. Miami, FL: Summy-Birchard, Inc. p.2.

Suzuki, S. (2003). Suzuki Cello School, Volume 7: Cello Part: Revised Edition. Miami, FL: Summy-Birchard, Inc. p.3. 
Suzuki, S. (2003). Suzuki Cello School, Volume 8: Cello Part: Revised Edition. Miami, FL: Summy-Birchard, Inc. p.3.

Suzuki.org.nz. (n.d.). Dr Shinichi Suzuki. [online] Available at: http://suzuki.org.nz/ [Accessed 28 Jun. 2019].

Suzuki.org.nz. (n.d.). Suzuki in NZ. [online] Available at: http://suzuki.org.nz/ [Accessed 28 Jun. 2019].

Suzukimethod.or.jp. (n.d.). The History of the "Talent Education Research Institute". [online] Available at: https://www.suzukimethod.or.jp/english/E_mthd111.html [Accessed 28 Jun. 2019].

The National Association for Music Educations. (2008). Child's Bill of Rights. [online] Available at:

https://web.archive.org/web/20080929204920/http://www.menc.org/resources/view/child-sbill-of-rights [Accessed 17 May 2019].

Watkins, Cornelia. [2016] The Swan. [online] CMP Teaching Plan. Available at: https://wmeamusic.org/files/2016/03/CMPtp2009_Studio_TheSwan.pdf. [Accessed 16 Nov. 2019]. p.1-2.

Wyatt, B. 2005, "Cello Forum: Considering the Source", American String Teacher. 55(3), p.36-38. 